\title{
Research Article \\ Hot Structure Flight Data of a Faceted Atmospheric Reentry Thermal Protection System
}

\author{
Hannah Boehrk (D), Hendrik Weihs, and Henning Elsäßer \\ Institute of Structures and Design, German Aerospace Center (Deutsches Zentrum für Luft- und Raumfahrt (DLR)), \\ Pfaffenwaldring 38-40, D-70569 Stuttgart, Germany \\ Correspondence should be addressed to Hannah Boehrk; hannah.boehrk@dlr.de
}

Received 17 December 2018; Revised 28 May 2019; Accepted 17 June 2019; Published 18 November 2019

Academic Editor: Marco Pizzarelli

Copyright (@ 2019 Hannah Boehrk et al. This is an open access article distributed under the Creative Commons Attribution License, which permits unrestricted use, distribution, and reproduction in any medium, provided the original work is properly cited.

\begin{abstract}
The second sharp-edged flight experiment is a faceted suborbital reentry body that enables low-cost in-flight reentry research. Its faceted thermal protection system consisting of only flat radiation-cooled thermal protection panels is cost-efficient since it saves dies, manpower, and storage. The ceramic sharp leading edge has a $1 \mathrm{~mm}$ nose radius in order to achieve good aerodynamic behaviour of the vehicle. The maximum temperature measured during flight was $867^{\circ} \mathrm{C}$ just before transmission ended and was predicted with an accuracy of the order of $10 \%$. The acreage thermal protection system is set up by 3 mm fiber-reinforced ceramic panels isolated by a $27 \mathrm{~mm}$ alumina felt from the substructure. The panel gaps are sealed by a ceramic seal. Part of the thermal protection system is an additional transpiration-cooling experiment in which nitrogen is exhausted through a permeable ceramic matrix composite to form a coolant film on the panel. The efficiencies at the maximum heat flux are $58 \%$ on the porous sample and $42 \%$ and $30 \%$ downstream of the sample in the wake. The transient load at each panel location is derived from the trajectory by oblique shock equations and subsequent use of a heat balance for both cooled and uncooled structures. The comparison to the heat balance HEATS reveals heat sinks in the attachment system while the concurrence with the measurement is good with only $8 \%$ deviation for the acreage thermal protection system. Aerodynamic control surfaces, i.e., canards, have been designed and made from a hybrid titanium and ceramic matrix composite structure.
\end{abstract}

\section{Introduction}

In 2001, Longo et al. and Eggers et al. have worked out a concept using sounding rockets for the purpose of establishing low-cost reentry flight opportunities for the investigation of in-flight aerothermodynamic phenomena $[1,2]$. Although expensive and complex, structural artifice supports this endeavour. Longo proposed a faceted sharp-edged concept as an initial flight experiment. The approach was to estimate the cost for two different thermal protection systems (TPS) for the reference vehicle HOPPER [1, 3, 4]: a curved-panel TPS and a flat-panel TPS. Longo et al. compared the results and have found that $70 \%$ of the cost for the hot structure can be saved in dies, man hours, and storage [1]. For each curved part, a respective die is needed for each process step. Moreover, the panels have to be laid up individually by hand into the complexly curved die, adding to the man hours. Finally, the die must be stored in case of a need for a replace- ment or a need for a second mission. Flat panels, on the contrary, can be shaped from the identical basic shape and milled into the necessary geometry which reduces the storage cost for moulds and replacement panels. The study showed that from an aerothermodynamic point of view, problems are faced from these sharp leading edges, steps, and gaps. They promote local stagnation areas that experience very high temperatures that have not been withstood by any material before. On the other hand, sharp leading edges are known to have minimum drag, require relatively low thrust during ascent, and achieve a higher cross-range during reentry leading to larger reentry windows, as opposed to blunt bodies [5]. Therefore, during the 1990s, the development of ceramic composite and ultrahigh-temperature material systems for TPS applications has led to a renewed interest in sharpedged configurations [1] such as the waverider concept F8 [6], the project JAPHAR [7], and the SHARP project [8]. The sharp-edged flight experiment presented here serves to 


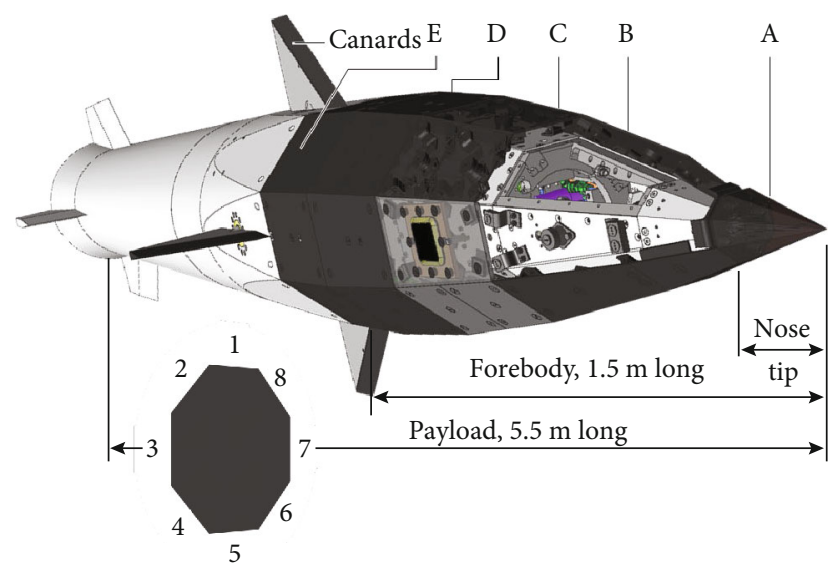

FIGURE 1: Sharp-edged flight experiment SHEFEX II.

investigate the practicability of the new materials for slender and controllable hypersonic flight vehicles. Although aspects like the aerodynamics at single flight points can be investigated in ground test facilities, the transient full scale qualification can be demonstrated only in flight.

With SHEFEX I, this novel system approach with the combination of all of these assets, has flown a return flight from a $200 \mathrm{~km}$ apogee for the first time in 2005 . It was proven by aerothermodynamic calculations and later validated against the SHEFEX I in-flight measurements that the thermal protection system can withstand the high temperatures that occur during return flight [9]. SHEFEX I performed successful reentry from $80 \mathrm{~km}$ at Mach 5.6 to $26 \mathrm{~km}$ at Mach 6.2 with the subsequent loss of the vehicle [10]. Lessons learned include the comparison of real flight data against numerical simulations and ground testing $[9,11]$.

Taking into account all the experience and collected flight data obtained during the SHEFEX I mission, the test vehicle was redesigned to a similarly faceted, sharp-edged reentry body SHEFEX II and extended by an active control system, which allows for active aerodynamic control during the atmospheric flight segment $[12,13]$. Unlike the nonsymmetric shape of SHEFEX I that provided natural lift during flight, SHEFEX II has an axis-symmetric shape in order to allow for only the control system to generate lift. Moreover, the axissymmetric shape provides the possibility to take measurements during ascent since no fairing is needed. As depicted in Figure 1, SHEFEX II has an octagonal cross section over a forebody length of $1.5 \mathrm{~m}$ at a height and diameter of $0.5 \mathrm{~m}$. It was launched by a two-stage sounding rocket system from Andøya, Norway, in spring 2012. The figure also shows the location nomenclature with the panel segments denominated in letters A though E.

This paper gives an overview over the thermal protection system (TPS) of the SHEFEX II vehicle in heritage of SHEFEX I. At first, the predicted trajectory is given. After the introduction of the SHEFEX II TPS material, the design of the structural key elements will be explained in Section 4. These comprise (a) the radiation-cooled faceted acreage panels and their attachment to the substructure; (b) the sharp leading edge, or vehicle tip; (c) the ceramic-based transpiration-cooled experiment AKTiV; and finally, (d) the

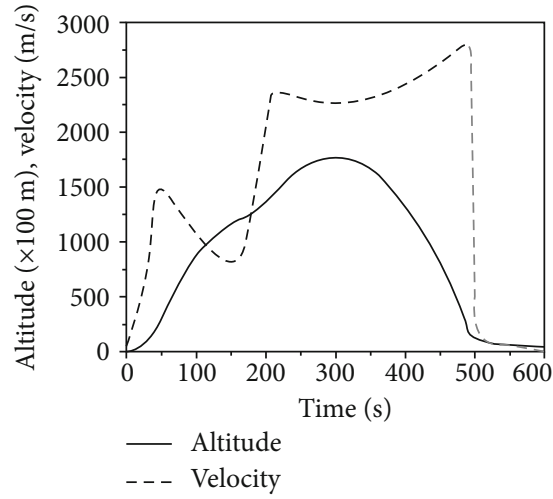

FIGURE 2: DMARS data of the SHEFEX II trajectory [14]. Black lines give in-flight measurement, and gray lines give the assumed subsequent flight path.

aerodynamic control surfaces, i.e., canards, in which the twofold requirements of high-temperature resistance and load bearingness are realized in a hybrid structure. Their design is described in Sections 4.1-4.4. The instrumentation enables comparison of measurements to the load predicting heat balance tool HEATS and thus interpretation of ground testing and flight data. The impressive flight data are presented and interpreted in Section 5. The paper focuses on the TPS structure and design of the vehicle SHEFEX II and demonstration of the general viability of these structural solutions. Results are provided in terms of recorded and transmitted flight data.

\section{The SHEFEX II Trajectory}

SHEFEX II was launched from the Andøya Rocket Range in Norway on June $22^{\text {nd }} 2012$. It flew approximately $800 \mathrm{~km}$ far in a north-west direction where it fell into the arctic sea west of Svalbard, being decelerated by a parachute. Figure 2 shows the data measured by the Digital Miniature Attitude Reference System (DMARS) during the SHEFEX II flight $[14,15]$. Black lines give in-flight measurement, and gray lines give the assumed subsequent flight path. The vehicle was launched by a two-stage Brazilian rocket configuration with an S-40 first stage and an S-44 second stage rocket motor. The rocket has delivered SHEFEX II, shown in the photograph of Figure 3, to an apogee of $\sim 180 \mathrm{~km}$. The total flight time was roughly $500 \mathrm{~s}$ comprising $52 \mathrm{~s}$ of experimental time for the atmospheric reentry between 100 and $30 \mathrm{~km}$.

All data were transmitted to a ground station at the Andøya Rocket Range. The connection lasted until SHEFEX II dove behind the horizon, corresponding to an altitude of $30 \mathrm{~km}$. The subsequent flight path is assumed to have followed the trajectory down to approximately $13 \mathrm{~km}$ when the payload was split, translated to a subsonic flight, and the parachute was released. A flotation bag transmitted a position signal after splashdown, but due to harsh weather in the landing region the vehicle could not be recovered before it sank. Within the experiment time, the vehicle had accelerated from $2559 \mathrm{~m} / \mathrm{s}$ and Mach 10.2 at $101 \mathrm{~km}$ altitude to $2791 \mathrm{~m} / \mathrm{s}$ and Mach 9.3 at $30 \mathrm{~km}$. 


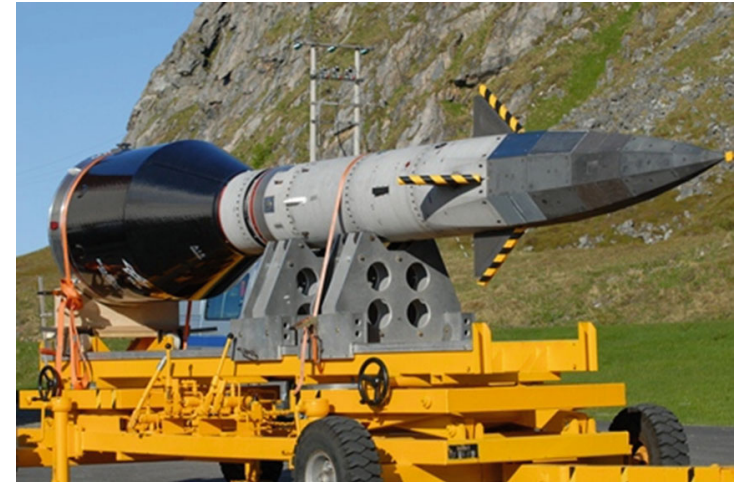

Figure 3: Payload of the SHEFEX II reentry vehicle upon rollout to the launcher.

During hypersonic reentry, a shock stands ahead of blunt shapes while it is attached to pointed shapes, since the shock distance decreases with leading-edge radius [16, 17]. Blunt bodies like Apollo or Soyuz are commonly used in order to increase the shock distance from the heat shield material to allow for the gas temperature close to the vehicle to be dissipated into the internal energy of the atmospheric gas, such as dissociation or vibration [16]. In the case of SHEFEX II, an oblique shock rises from the sharp pointed nose with very low shock distance. Downstream from the oblique shock, the air is expanded at the facet corners. Figure 4 illustrates the flow phenomena on the example of panels A and B of SHEFEX II. The TPS designer must account for the thermomechanical loads onto the vehicle. However, since access to space is costly, overdesign must be avoided. Therefore, the TPS designer needs to lay out the heat shield against transient loads, considering also the heat capacity of the heat shield material. The challenges addressed in SHEFEX II are the design of the sharp leading edge, the faceted acreage TPS, the active transpiration cooling, and the canard surfaces for controlled hypersonic flight and attitude. During heat shield design, it is necessary to estimate the heat flux from a fluid flow to a surface. Especially when the surface is actively cooled, such as with film, transpiration, or effusion cooling, the determination of the heat transfer coefficient is difficult to assess. The computer program HEATS (Heat Exchange Analysis for Transpiration Systems) is used to determine the transient wall temperature throughout the entire reentry trajectory or ground-testing experiment. It has been validated by comparison to experiments in both a steady-state archeated wind tunnel under laminar in-flow and short duration measurements in a shock tube $[18,19]$.

\section{Material}

The present paper gives an overview of the different parts of the SHEFEX II thermal protection system. The SHEFEX II acreage TPS is made from a ceramic matrix composite (CMC). The fiber ceramic C/C-SiC, used for the SHEFEX II TPS, is a composite consisting of carbon fibers with a matrix of carbon and silicon carbide. It was qualified in plasma wind tunnel testing in numerous campaigns since the 1980s and during real reentry flight, such as in the FOTON9, EXPRESS,
FOTON-M2, and the SHEFEX I and II missions. The material is lightweight with a density of $1900 \mathrm{~kg} / \mathrm{m}^{3}$. Up to temperatures as high as $2000 \mathrm{~K}$, this material has stable properties with respect to Young's modulus, strength, and tensile strain. Moreover, with large damage tolerance, it is resistant to thermoshock [20] at low thermal expansion in a ply direction of only $1.5 \times 10^{-6} \mathrm{~K}^{-1}$ [21]. The carbon fibers, however, are oxidation sensitive with $<3 \mathrm{~kg} / \mathrm{m}^{2} \mathrm{~h}$ specific mass loss below $1900 \mathrm{~K}$ and $>10 \mathrm{~kg} / \mathrm{m}^{2} \mathrm{~h}$ above $2100 \mathrm{~K}$. When coated, the material withstands high-temperature loads up to $1970 \mathrm{~K}$, being fully reusable with negligibly small specific mass loss rates below $0.1 \mathrm{~kg} / \mathrm{m}^{2} \mathrm{~h} \mathrm{[22].}$

The manufacturing of $\mathrm{C} / \mathrm{C}-\mathrm{SiC}$ has been widely reported [23]. The intermediate stage $\mathrm{C} / \mathrm{C}$ (carbon-fiber-reinforced carbon) has intriguing permeable properties. The good permeability of the $\mathrm{C} / \mathrm{C}$ produced during DLR's pyrolysis step is used in transpiration cooling in which a cooling fluid is fed through the structure into the boundary layer, as will be introduced for the flight experiment AKTiV. The microcracks in the low-density carbon matrix serve as open pores for the fluid transfer. The pores distribute the coolant evenly over the hot facing surface to keep it cool and enable it to withstand exposure to high temperatures. The permeability of the $\mathrm{C} / \mathrm{C}$ used for the hypersonic in-flight transpirationcooling experiment AKTiV in 2012 is on the order of $10^{-13} \mathrm{~m}^{2}$. The porosity is relatively high at $12 \%$. A coolant film may also provide oxidation protection for the structure. Since material properties are adjustable by choice of rovings and stacking of plies, both conductivity and permeability can be optimized to the values necessary for the application. Table 1 compares the thermal properties of $\mathrm{C} / \mathrm{C}$ and $\mathrm{C} / \mathrm{C}-\mathrm{SiC}$.

$\mathrm{C} / \mathrm{C}-\mathrm{SiC}$, as presented here, is the material used for the SHEFEX II thermal protection system. The majority of the key components of the TPS described in the following section are based on this material. Table 1 additionally gives thermophysical properties of Ti6Al4V which is used in the hybrid design of the control surfaces, i.e., canards, described in Section 4.4 .

\section{Faceted Thermal Protection System}

The primary structure of the forebody consists of an aluminum substructure created by stiff ribs and stringers. The open volume is then closed by flat aluminum panels which create an inner mould line. These aluminum panels are used for mounting the TPS facets and experiments. Inside the aluminum substructure, the in-flight measurement infrastructure is integrated. These are thermocouple connection and compensation, pressure transducers, a pyrometer system, and data processing boxes.

As explained above, the forebody geometry is symmetrically divided into eight identical facets 1 through 8 in a circular direction and five lengthwise segments A through E, as marked in Figure 1. All in all, the payload houses 40 single flat areas. The challenging parts are the attachment of the panels to the cold substructure, providing sufficient insulation to the aluminum and interpanel sealing. Before flight, the entire payload forebody has undergone vibration testing. 


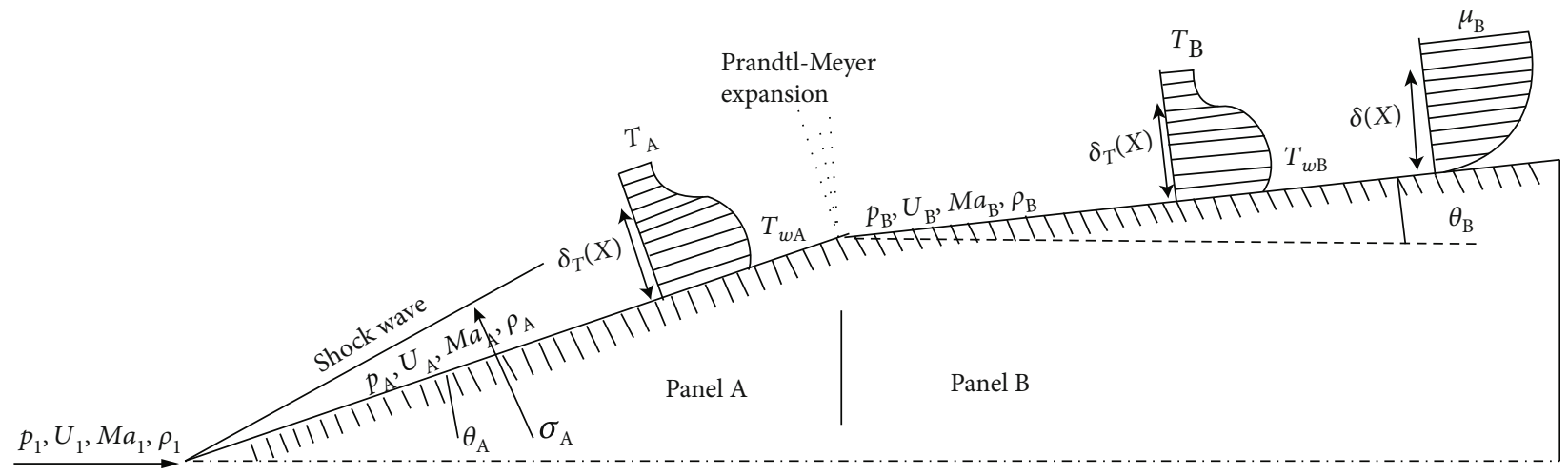

FIgURE 4: SHEFEX II shock and expansion areas.

TABLE 1: Material properties of C/C, C/C-SiC, and titanium Ti6Al4V. C/C-SiC is given in its orthotropic properties which are comparably constant over temperature. Titanium properties are given with respect to room temperature (RT) and high temperature (HT) of approximately $800 \mathrm{~K}$.

\begin{tabular}{|c|c|c|c|c|c|c|c|c|}
\hline & $\begin{array}{c}\rho \\
\left(\mathrm{kg} / \mathrm{m}^{3}\right)\end{array}$ & $\epsilon$ & $\begin{array}{c}\lambda_{\|} \\
(\mathrm{W} / \mathrm{mK})\end{array}$ & $\begin{array}{c}\lambda_{\perp} \\
(\mathrm{W} / \mathrm{mK})\end{array}$ & $\begin{array}{c}c_{p} \\
(\mathrm{~J} / \mathrm{kg} \mathrm{K})\end{array}$ & $\begin{array}{c}\alpha_{\mathrm{TE}, \|} \\
\left(10^{-6} \mathrm{~K}^{-1}\right)\end{array}$ & $\begin{array}{c}\alpha_{\mathrm{TE}, \perp} \\
\left(10^{-6} \mathrm{~K}^{-1}\right)\end{array}$ & $\begin{array}{c}\sigma \\
(\mathrm{MPa})\end{array}$ \\
\hline $\mathrm{C} / \mathrm{C}$ & 1400 & 0.85 & 14 & 2 & 1650 & & & \\
\hline $\mathrm{C} / \mathrm{C}-\mathrm{SiC}$ & 1900 & 0.85 & 17 & 8 & 1350 & 1.5 & 5 & 160 (bending) \\
\hline \multirow[t]{2}{*}{ Ti6Al4V } & 4430 & & 7.1 & 7.1 & 560 & $2.6(\mathrm{RT})$ & & $900(\mathrm{RT})$ \\
\hline & & & & & & $3(\mathrm{HT})$ & & $550(\mathrm{HT})$ \\
\hline
\end{tabular}

The tests have shown that the SHEFEX II payload remains safe with an identical eigen frequency before and after the test.

In this chapter, the overall faceted TPS will be described and its attachment to the substructure will be addressed. Subsequently, the set-up, attachment, and instrumentation of the sharp leading edge will be introduced. Finally, the transpiration-cooled experiment AKTiV, the world first transpiration-cooled flight experiment, will be described. Finally, the aerodynamic control surfaces, with their hybrid titanium and ceramic matrix composite structure are presented.

4.1. Faceted Acreage TPS. The basic TPS system is based on the segmented FESTIP concept developed in the 1990s [24].

It facilitates multiuse, low maintenance, and rapid turnaround time for the exchange of TPS panels and is shown in Figure 5. The main element of the concept is the hot CMC panel, supported in all directions by a central post and flexible standoffs at the four corners, so that the panel's thermal expansion is not suppressed [25]. Between the panel and the cold aluminum structure, an alumina felt insulation material is laid out. The SHEFEX standard C/C-SiC panel thickness is $3 \mathrm{~mm}$, and the alumina insulation thickness is $27 \mathrm{~mm}$. This results in an extremely thin overall TPS thickness of $33 \mathrm{~mm}$, including the aluminum panel, making room for the payload and instrumentation. Each flat panel was instrumented with three thermocouples and a pressure port $[26,27]$.

As mentioned, one key issue of the design concept is the hot connection of the panels to the CMC standoff by

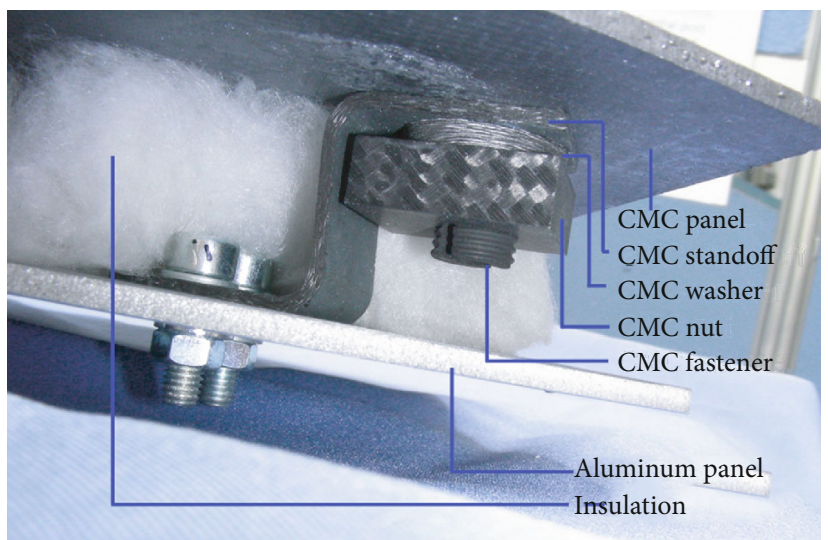

Figure 5: SHEFEX II thermal protection system set-ups [31].

fasteners in the high-temperature regime of up to $1800 \mathrm{~K}$. These fasteners must enable panel attachment and removal having only external access to the TPS. A rivet-type fastening bolt was therefore developed, tested, and optimized, combining the function of a screw and a rivet [28-30]. It is shown in Figure 6. A total of 180 screw rivets are necessary for assembly of the flight unit.

Another key element for the TPS is the interpanel seal [32]. Seals are used to protect the area where two panels are joined but not connected. For temperatures around $1700 \mathrm{~K}$, a thermal expansion

$$
\Delta l=L_{\text {panel }} \alpha_{\mathrm{TE}} T,
$$




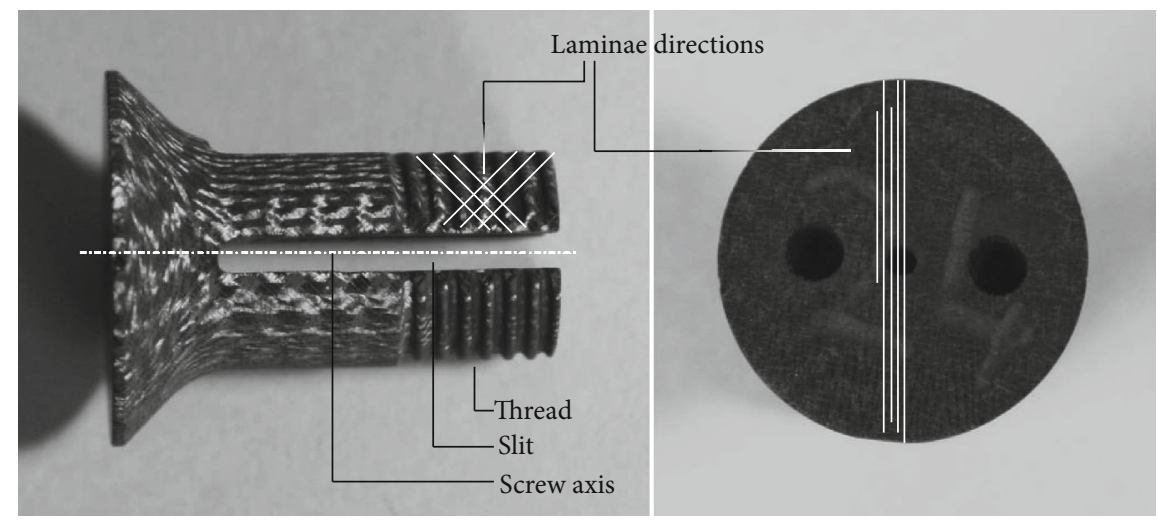

Figure 6: Fastener side and top views [30].

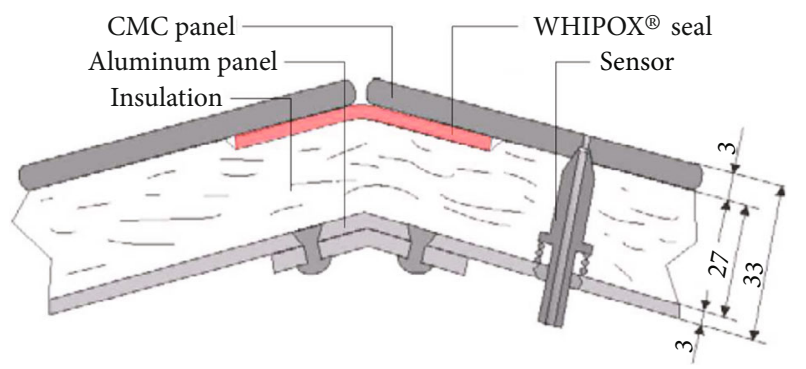

Figure 7: WHIPOX ${ }^{\circledR}$ seal between facets [31].

of up to $0.765 \mathrm{~mm}$ has to be taken into account lengthwise for the panels. Therefore, a gap has to be foreseen to allow for the panels to expand freely without conflicting with each other. In order to prevent hot gas from intruding into the vehicle or even into the insulation of the TPS, the gap needs to be covered. Alumina-based WHIPOX has a flexible intermediate state during the manufacturing process, in which it is possible to shape a component such as the SHEFEX rigid seal during forebody assembly. Using this property, it is possible to shape and cut all required seal components from one uniform WHIPOX tape as shown in Figure 7.

In segment $\mathrm{C}$, every other panel is from a radiofrequencytransparent WHIPOX alumina ceramic matrix composite in order to transmit the signal from a patch antenna. WHIPOX is, thus, used as an oxidation-resistant alternative to carbonbased CMC. A special feature of these CMCs is their inherent transparency for electromagnetic waves, making them attractive as thermal protection for antennae. However, the emissivity of alumina is low and, consequently, the radiation cooling capability of alumina-based TPS panels is limited. In order to prevent thermal overload, the emissivity of CMC is improved by superficial impregnation and coating with an oxidation-resistant "black" CoFe-spinel [33]. It has been shown that $\mathrm{CoFe}$-spinel surface modification reduces the CMC temperatures by more than $200 \mathrm{~K}$ in a Mach 6 hypersonic flow field [33]. Moreover, the large coefficient of thermal expansion of roughly $7 \times 10^{-6} \mathrm{~K}^{-1}$ (see Table 1 for comparison) causes a strong bending momentum within the flexible CMC standoffs. At the expected $1500 \mathrm{~K}$ at panel $\mathrm{C}$, resulting in a thermal expansion of $2.7 \mathrm{~mm}$, the momentum is too large for the standoffs. In order to account for these effects, the WHIPOX panels are split into two parts, thus bisecting the expansion on each half panel to $1.35 \mathrm{~mm}$. The momentum in the standoffs is thus diminished and another gap is introduced between the half panels, in turn, sealed by a WHIPOX seal.

The faceted set-up of SHEFEX II has been shown to be cost-efficient compared to curved parts. In contrary to flat panels, each curved part needs a respective die for each process step, i.e., tempering of the CFRP green body and pyrolysis, and has to be laid up individually by hand into the complexly curved die. SHEFEX II consists of 40 flat TPS panels in segments $B$ through $\mathrm{E}$, made from identical raw material plates. The set-up has the advantage of being able to integrate experiments from potential clients with one single interface specification [34-37].

4.2. Sharp Leading Edge. Figure 8 shows the sharp leadingedge design. The octagonal pyramid shape was milled from solid material and has a mass of around $680 \mathrm{~g}$. The radius of the sharp leading edge was investigated with a profile projector and determined to be $0.8 \mathrm{~mm}$. The tip is attached to the vehicle by a mount from thin-walled $\mathrm{C} / \mathrm{C}-\mathrm{SiC}$ material, as shown at the very left of the side view in Figure 8. The mount is composed of two half shells, joined by joining elements, and an inlay. The inlay has four screw bores through which, by means of four $\mathrm{C} / \mathrm{C}-\mathrm{SiC}$ fasteners, the tip is attached to the mount [30]. The thin-walled mount, in turn, is attached to the aluminum substructure by Z-shaped CMC standoffs.

The instrumentation of the sharp leading edge during reentry flight comprises bores for both pressure measurement and thermocouples. These measurements are used to reconstruct flight attitude [38]. The bores for the flush air data system have been electrical discharge machined into the material. Three sheathed type-S-thermocouples with $1 \mathrm{~mm}$ diameter and isolated hot junctions were located far upstream in the leading edge at approximately $5 \mathrm{~mm}$ beneath the surface as shown in Figure 9 in the bottom cut view. Additionally, the solid $\mathrm{C} / \mathrm{C}-\mathrm{SiC}$ tip contains pressure ports on its eight facets in the shape of slender bore holes leading to the aft side of the tip. The pressure bores must be connected to the pressure transducers by metallic tubing because mounting the transducer directly to the tip is not possible due 


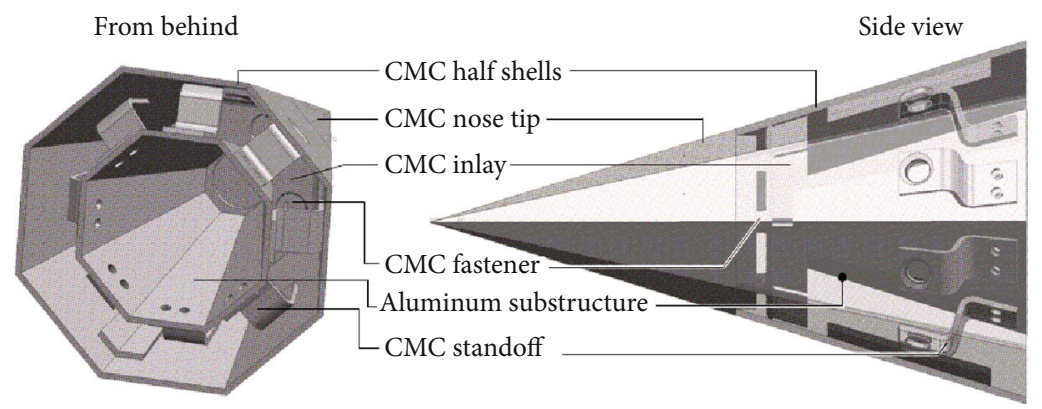

Figure 8: SHEFEX II C/C-SiC sharp leading-edge design.
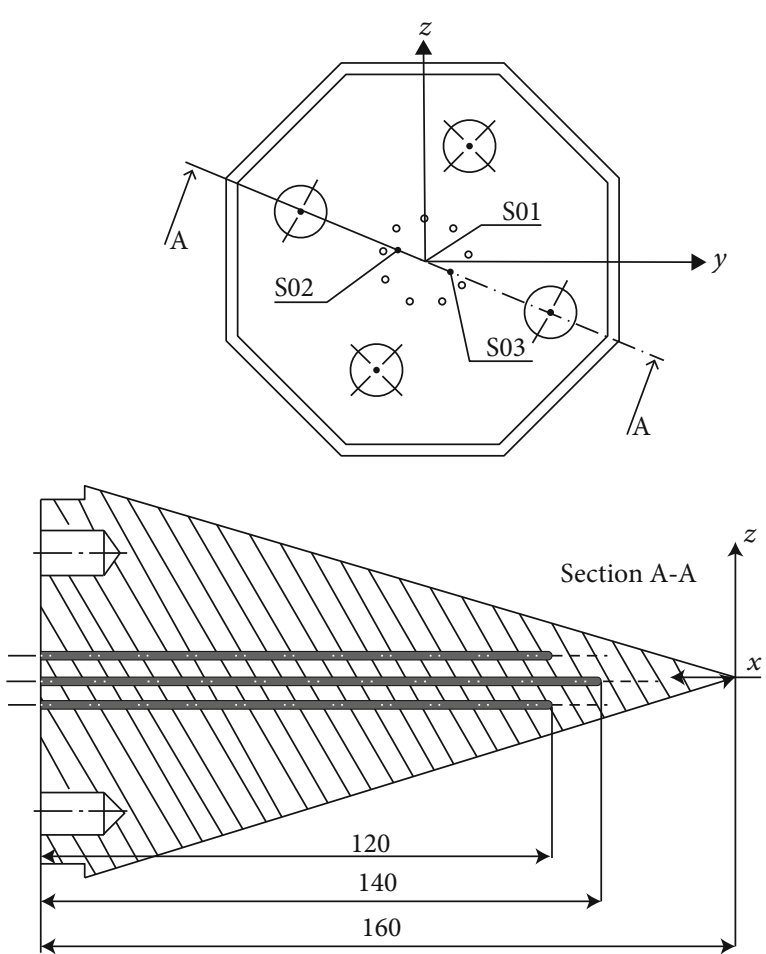

FIGURE 9: Leading-edge instrumentation.

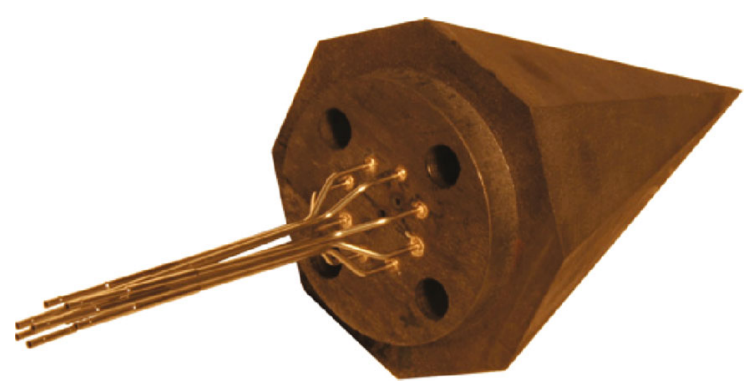

FIgURE 10: SHEFEX II sharp leading edge with pressure routing.

to geometrical and thermal constraints. Therefore, eight Inconel tubes have been soldered into the ceramic matrix composite in order to make the connection, see Figure 10.

A duplicate was ground-tested in an arc-heated wind tunnel in a representative condition for the loads imposed by the flight trajectory [39]. Additionally, the surface temperature was measured by an infrared camera and pyrometers. The results of the ground testing show that the temperatures at the interior thermocouple positions are well predicted by the heat balance from HEATS with accuracies of 3 and $11 \%$ [39]. Also, the ground measurement with an IR camera is predicted with $6 \%$ accuracy.

4.3. Transpiration-Cooled Experiment AKTiV. The ceramic matrix composite $\mathrm{C} / \mathrm{C}-\mathrm{SiC}$ serves as a passive, radiatively cooled heat shield of the SHEFEX II thermal protection system. Lately, in the discussion of reusable space transportation, active cooling systems have gained special interest when it comes to severe thermal environments where the passive systems are insufficient. One experiment on SHEFEX II, AKTiV, was dedicated to this topic.

Transpiration-cooled rocket engines fabricated from porous CMC material have been investigated for a couple of years [40]. This technology, in which a coolant is forced through a permeable wall component by a pressure gradient, has recently been transferred to reentry load cases. CMCs are candidate materials for transpiration cooling as they can be produced within a variety of open porosity and permeability characteristics. The described prestate of the TPS material $\mathrm{C} / \mathrm{C}$ has a natural porosity and permeability and still withstands the mechanical and thermal loads as specified for TPS. However, it consists of carbon and is thus extremely prone to oxidation at temperatures above $700 \mathrm{~K}$.

Transpiration cooling, as referred to here, is effected by two physical phenomena. The first being convectioncooling of the wall material by the coolant as it is fed through the permeable structure. The other one is the lowering of the heat transfer from the high-enthalpy environment to the vehicle surface by forming a coolant layer or film on the outer-hot-surface as shown in Figure 11. Moreover, a coolant film - for example of nitrogen-also provides oxidation protection for the structure which may be an important issue in the case of carbon-based materials.

AKTiV was located on panel C3, see Figure 1. A nonpressurized reference set-up was mounted on the opposite panel C7 where-at zero sideslip angle-the same ambient flow conditions were expected. HEATS is a lay-up tool for the determination of transient wall heat flux to a transpirationcooled parallel flat plate under laminar or turbulent flow conditions. It was developed for the lay-up of the experiment and later for the interpretation of the results. The method 


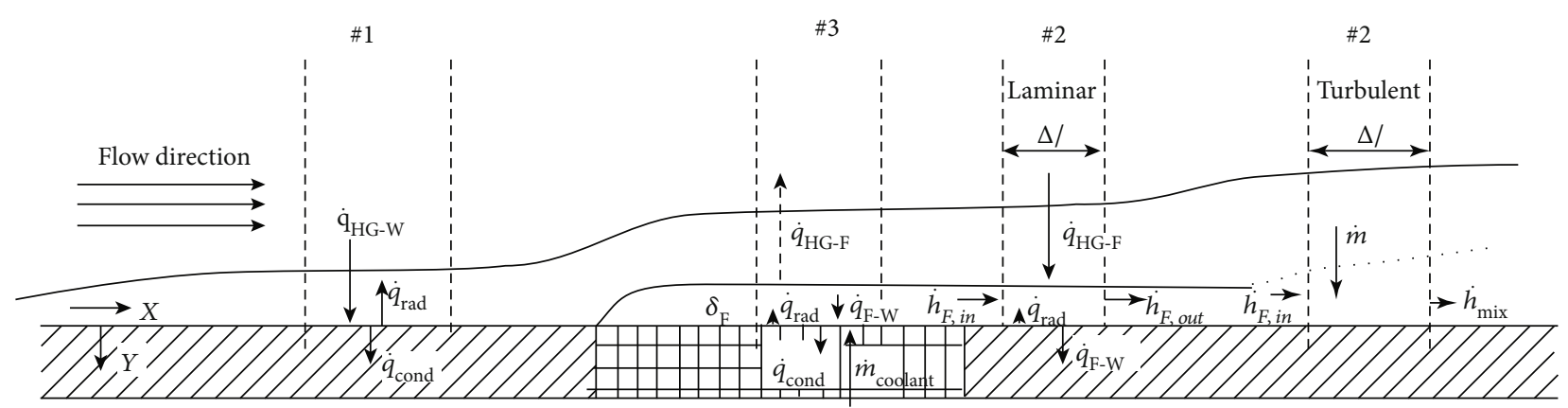

FIGURE 11: HEATS heat balance concept for transpiration cooling [18].

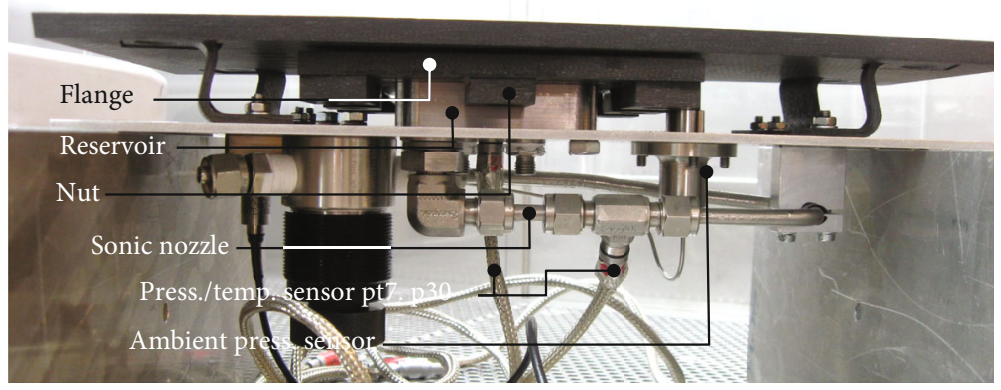

FIgURe 12: AKTiV side view.

is based on heat balances between wall material, transpired coolant, and surrounding hot gas. The problem is approached in three steps, sketched in Figure 11. Step 1 includes the heat flux to the panels as in a parallel plate case. The heat balance for the surface in this case equals

$$
\dot{q}_{\mathrm{HG}-\mathrm{W}}=\dot{q}_{\mathrm{rad}}+\dot{q}_{\mathrm{cond}},
$$

with index $\mathrm{HG}-\mathrm{W}$ indicating heat transfer from the hot gas to the wall. Step 2, addressed in region \#2 of Figure 11, additionally takes into account the thermal blocking by a coolant layer (film cooling) that in the case of the experiment presented here is injected through the porous material $\mathrm{C} / \mathrm{C}$. The heat balance for the surface remains

$$
\dot{q}_{\mathrm{F}-\mathrm{W}}=\dot{q}_{\mathrm{rad}}+\dot{q}_{\mathrm{cond}},
$$

with index $\mathrm{F}-\mathrm{W}$ for the heat transfer from the film to the wall. Step 3 addresses all three effects, heat flux from the hot gas to the film $\dot{q}_{\mathrm{HG}-\mathrm{F}}$, from the film to the wall $\dot{q}_{\mathrm{F}-\mathrm{W}}$, and heat transfer from the hot wall to the transpired coolant as the coolant temperature increases according to the heat equation for the wall,

$$
\rho_{\mathrm{mat}} c_{p, \mathrm{mat}} \frac{\partial T_{\mathrm{mat}}}{\partial t}=\lambda_{x} \frac{\partial^{2} T_{\mathrm{mat}}}{\partial x^{2}}+\lambda_{y} \frac{\partial^{2} T_{\mathrm{mat}}}{\partial y^{2}}-\alpha_{V}\left(T_{\mathrm{mat}}-T_{\mathrm{F}}\right)
$$

and the one for the gas, accordingly,

$$
\rho_{\mathrm{F}} c_{p, \mathrm{~F}} \frac{\partial T_{\mathrm{F}}}{\partial t}=\frac{\partial\left((\dot{m}(x, y) / A) c_{p, \mathrm{~F}} T_{\mathrm{F}}\right)}{\partial x}+\alpha_{V}\left(T_{\mathrm{mat}}-T_{\mathrm{F}}\right)
$$

Figures 12 and 13 show the set-up of the experiment on the SHEFEX II reentry vehicle. In the center of a $7 \mathrm{~mm}$ thick thermal protection panel, a porous $\mathrm{C} / \mathrm{C}$ $5 \mathrm{~mm}$ thick sample of the dimensions $61 \times 61 \mathrm{~mm}^{2}$ is inserted. This porous sample is to be run through by the coolant and is flanged into the surrounding TPS panel by a pressure reservoir and riveted ceramic fasteners [29, 30]. The reservoir itself is made of stainless steel. The panel and sample are tightened against sneak flows by graphite SIGRAFLEX felt.

The system consists of a pressurized tank, a pressure regulator, and a valve on the vehicle side of the experiment, and another pressure regulator, a mass flow controller (sonic nozzle), sensors, and data acquisition on the payload side of the experiment. A photograph of the entire set-up is shown in Figures 12 and 13. The hot panel of AKTiV is instrumented with thermocouples as shown in Figure 14. The picture also shows the groves where Z-shaped standoffs are attached to carry the hot panel.

Especially downstream of the porous sample, the thermocouples serve to monitor the effect of the film cooling redundantly, but also locally resolved, as shown in 


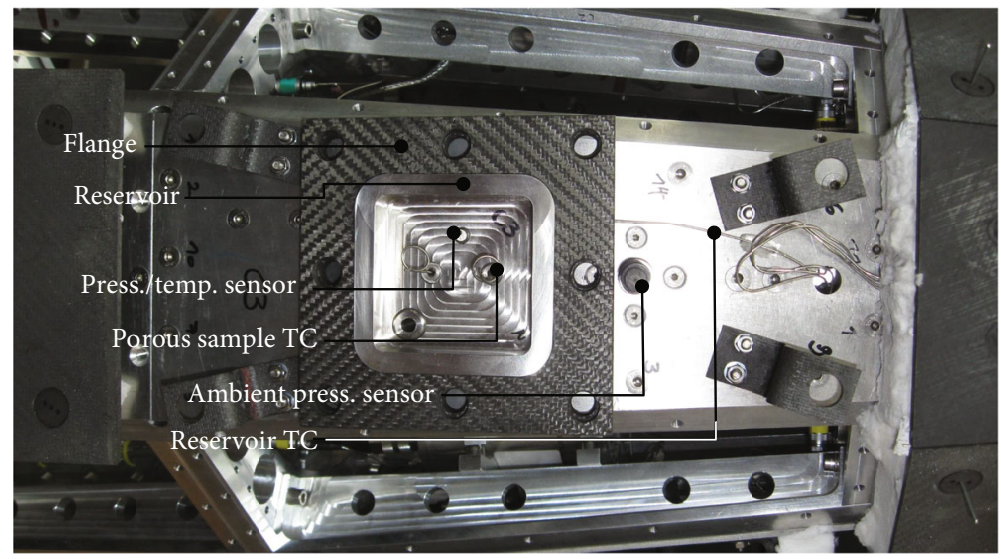

FIGURE 13: AKTiV interior instrumentation.

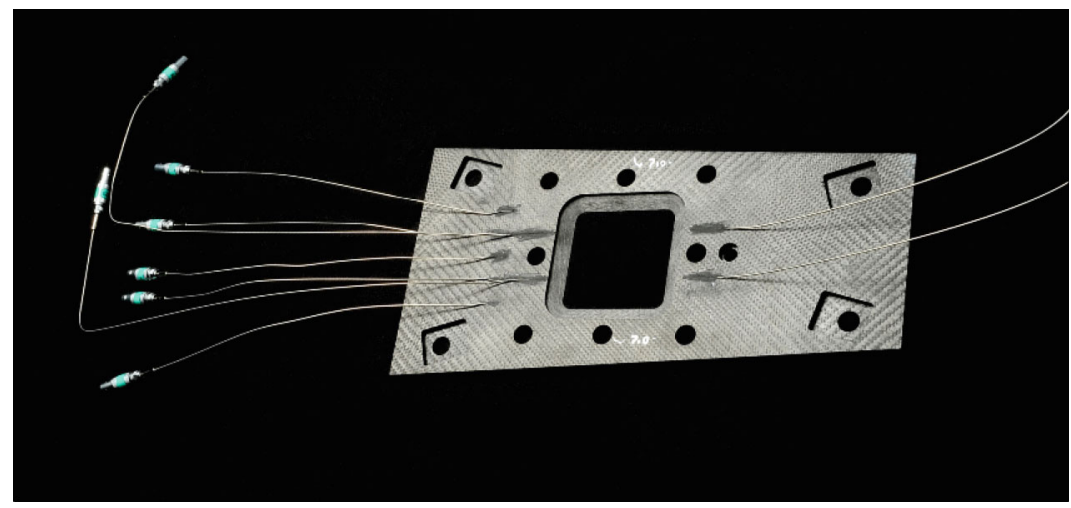

FIgURE 14: AKTiV panel instrumentation.

Figure 15(a). The reference module on panel C7 has monitored the uncooled behaviour of the set-up, as shown in Figure 15(b). A direct comparison of cooled and uncooled wall temperature $T_{\mathrm{W}}$ with reference to coolant temperature $T_{c}$ allows for assessment of the cooling efficiency,

$$
\eta=\frac{T_{\mathrm{W}, \text { uncooled }}-T_{\mathrm{W}}}{T_{\mathrm{W} \text {,uncooled }}-T_{\mathrm{c}}},
$$

of the transpiration cooling by AKTiV. Reservoir pressure is measured with a Kulite HKL/T-1-235 (M) combined pressure (p29) and temperature (pt6) sensor screwed at the bottom of the reservoir $[41,42]$.

4.4. Sharp Leading Edges in Canards. Another experiment onboard is dedicated to the attitude and roll control during reentry by means of the so-called canards, also shown in Figure 1. The canards are to stabilize the forebody during reentry by damping out rolling, pitching, or coning $[12,13]$. They are mounted onto the flat surfaces of the canard module that transfers the octagonal forebody shape to the cylindrical rocket modules. Four independent actuators, mechanically guarded within a secure maximum deflection of $15^{\circ}$, drive the canards. For transportation reasons, the canards have to be able to be mounted and secured from external access only.

Control surfaces are load bearing, and this issue requires additional consideration during their design. Like any structural part in flight experimentation, the canards have to withstand all thermal and mechanical loads while being lightweight. However, in order to reach the sufficient efficiency of the canards at altitudes above $60 \mathrm{~km}$ with low static air pressure, they are oversized for the lower altitudes. Consequently, extreme thermomechanical loads are encountered at low altitudes of $20 \mathrm{~km}$, which defines the end of the SHEFEX II experiment. The major challenge of the canard design is thus to withstand the resulting high mechanical load at the canard pivot in combination with the high thermal loads at the leading edges.

The design point is a worst case scenario as in the case of a malfunction in the canard actuators in which the canard would keep a constant maximum canard deflection of $15^{\circ}$ throughout the entire experiment phase, where the maximum mechanical canard load is $F_{\text {canard }}=10 \mathrm{kN}$ [43]. This is equivalent to a pressure difference of 1.8 bar on the canard surfaces. The load in the outer fiber of a potential C/C-SiC pivot is deduced as follows. The load reduction to the pressure point of the canard and the pressure point approximated 


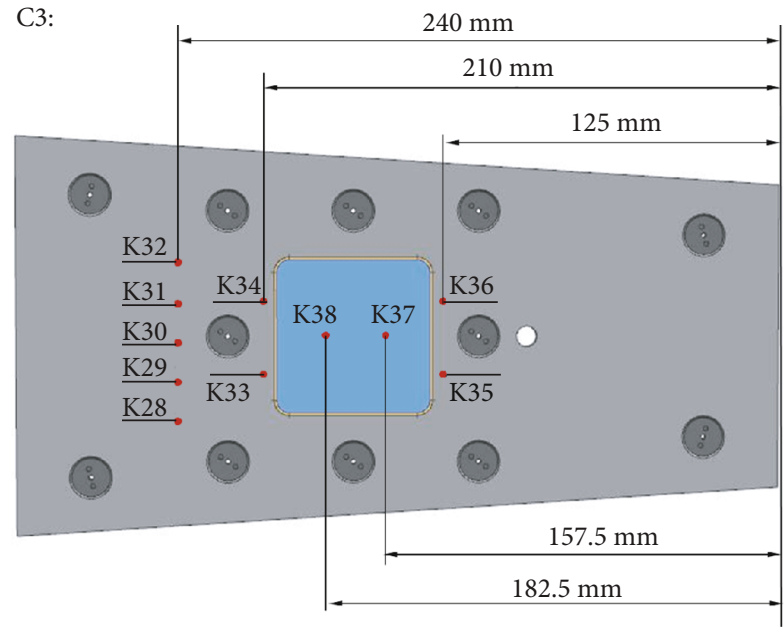

(a)

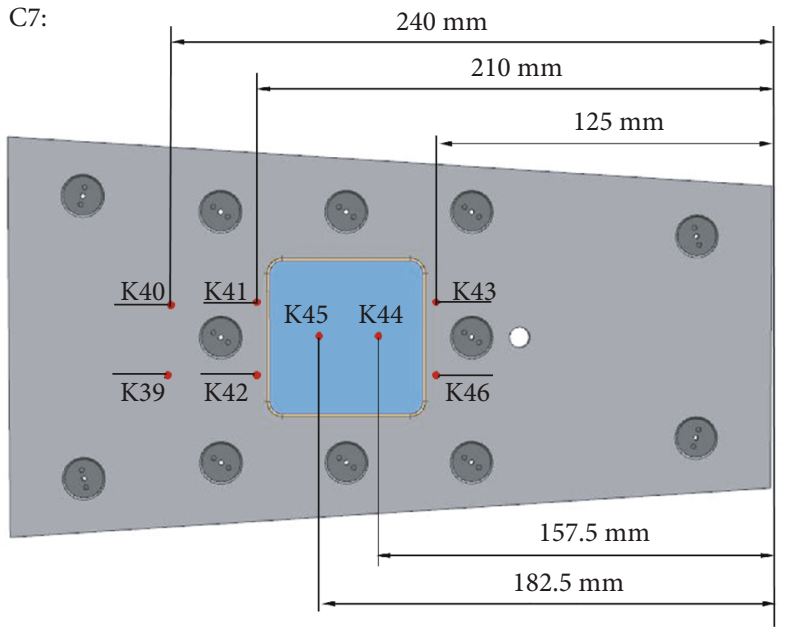

(b)

Figure 15: AKTiV thermocouple locations on the experiment (C3) and the reference (C7).

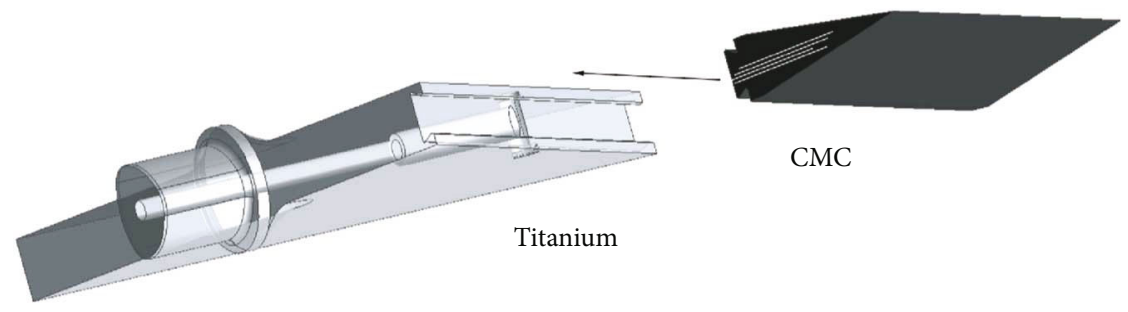

FIgURE 16: Dovetail principle.

in the area focus of the triangular canard, i.e., with a lever arm of $l=75 \mathrm{~mm}$, the momentum in the pivot yields $750 \mathrm{Nm}$ with

$$
M_{\text {pivot }}=l F_{\text {canard }}
$$

With pivot diameter $d=40 \mathrm{~mm}$ and area moment of inertia of an approximate circular cross section $I=\pi r^{4} / 4$, the load in the outer fiber,

$$
\sigma_{\mathrm{of}}=\frac{M_{\text {pivot }}}{I} \frac{d}{2}
$$

results in approximately $375 \mathrm{MPa}$. Table 1 gives strength, thermal expansion coefficient, and failure temperature for $\mathrm{C} / \mathrm{C}-\mathrm{SiC}$, indicating that the ceramic cannot endure the stress resulting from the equation above. A hybrid canard design was therefore chosen using a metallic main structure at the pivot and a CMC as the leading edge.

The sharp leading edge of the hybrid canard is made from $\mathrm{C} / \mathrm{C}-\mathrm{SiC}$, and the main structure including the pivot is made from titanium. This choice of material combination accounts for similar coefficients of thermal expansion, given in Table 1 . Titanium, moreover, has a high strength and low density. For joining of the two structural parts from CMC and titanium, a dovetail principle is applied as shown in Figure 16. To secure the $\mathrm{CMC}$ at the titanium, it is locked with a CMC pin. The dovetail compensates for the remaining difference in thermal expansion by permitting displacement of the components in length direction. The leading edge's laminae lay-up is also indicated in Figure 16. In thickness, i.e., out of plane of the C/C-SiC, the thermal expansion coefficients of both materials are comparable, as shown in Table 1, guaranteeing a tight conjunction throughout the whole flight. Due to the higher coefficients of the thermal expansion in ply direction, the titanium is expected to elongate beyond the $\mathrm{C} / \mathrm{C}-\mathrm{SiC}$ edges and pull the $\mathrm{C} / \mathrm{C}-\mathrm{SiC}$ by frictional effects. The maximum but uncritical load of $45 \mathrm{MPa}$ resulting from this effect is located at the CMC safety pin from Figure 17.

As mentioned above, for transportation reasons, the hybrid structure must allow for mounting from external access only. The titanium part can be slipped onto the canard module at first, followed by sliding in the CMC leading edge and securing it with a pin. The mounting procedure is depicted in Figure 17.

The sharp leading edge is not coated, so oxidation is expected to a certain extent. This is however tolerated, since erosion is expected to take only a few millimeters of the leading edge. The main titanium structure is also expected to locally overheat.

Both structural parts are mechanically loaded under their limits by factors of 1.5 . In the titanium structure, the 


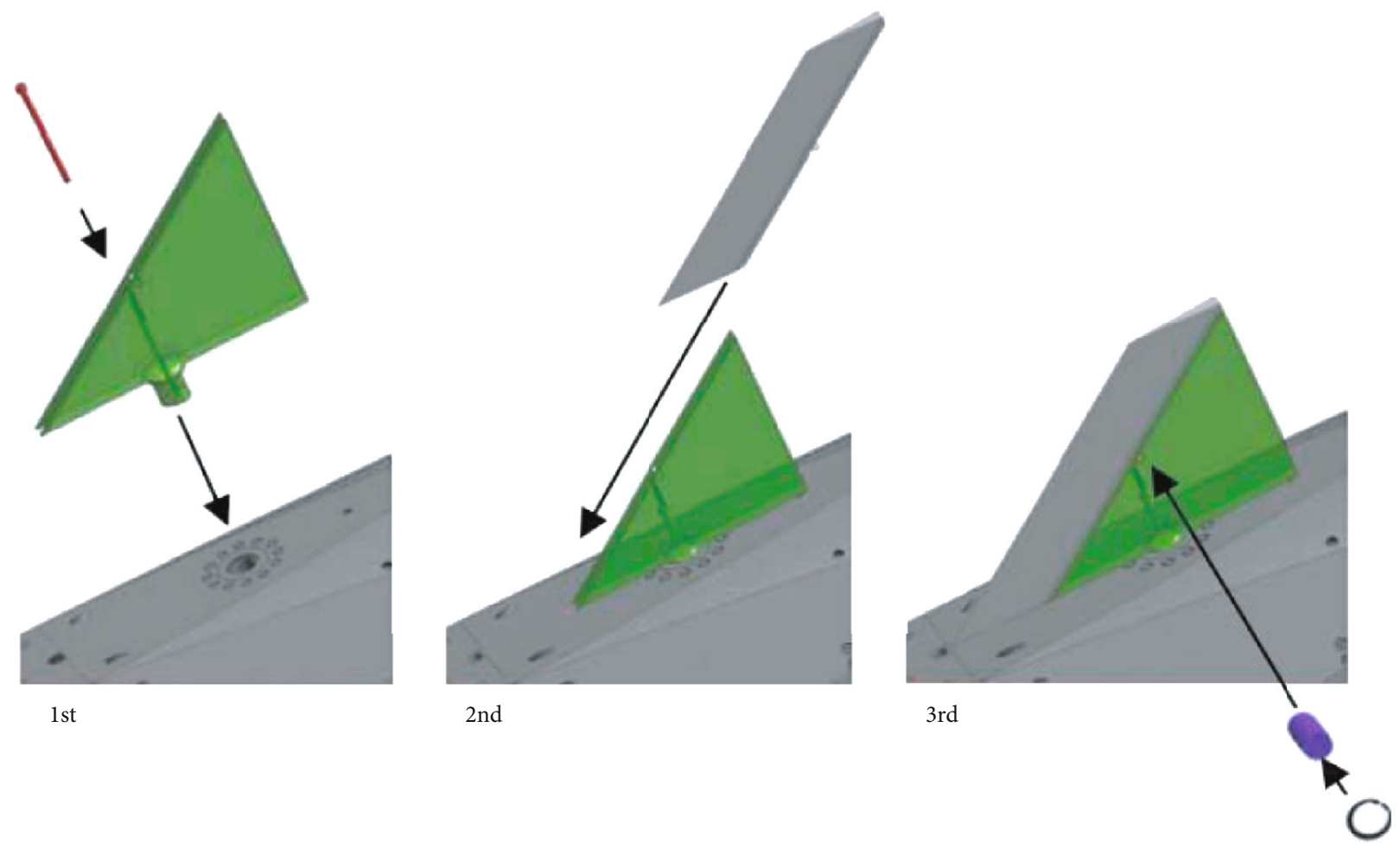

FIGURE 17: Mounting order for the CMC-titanium hybrid canard structure.

maximum stress appears at the pivot and in the $\mathrm{C} / \mathrm{C}-\mathrm{SiC}$ at the dovetail inner radius.

\section{SHEFEX II Flight Data from the TPS}

Flight measurements have been transmitted to a ground station during the SHEFEX II flight. The data were transferred from the launch until the vehicle disappeared behind the horizon at $t=485.12 \mathrm{~s}$ and $h=29.2 \mathrm{~km}$. It is not known how far down the vehicle has withstood the thermal and aerodynamic load beyond this point. However, temporary reception of the parachute signal in the foreseen impact area indicates that the rest of the flight has passed according to plan. It can thus be concluded that the leading edge has successfully passed the aerothermal loads of the SHEFEX II flight. The data interpreted here for the TPS address mainly thermocouple measurements. The model HEATS serves to interpret the data and to reconstruct $\dot{q}$ onto the wall.

5.1. Faceted TPS. Since the payload was rotationally symmetric and no payload fairing was necessary, atmospheric and payload response data could be recorded even during ascent. Each panel of the four instrumented quadrants 1, 3, 5, and 7 (see Figure 1 for nomenclature) was equipped with three thermocouples along its lengthwise axis of symmetry $[26,27,44]$.

Figure 18 shows the measured temperatures at the foremost thermocouple position along panel row 5 over the entire flight time. The figure shows that all panels faced a peak heating during ascent, with a maximum at $h=32 \mathrm{~km}$ altitude and $u=1490 \mathrm{~m} / \mathrm{s}$ after approximately $49 \mathrm{~s}$ flight time

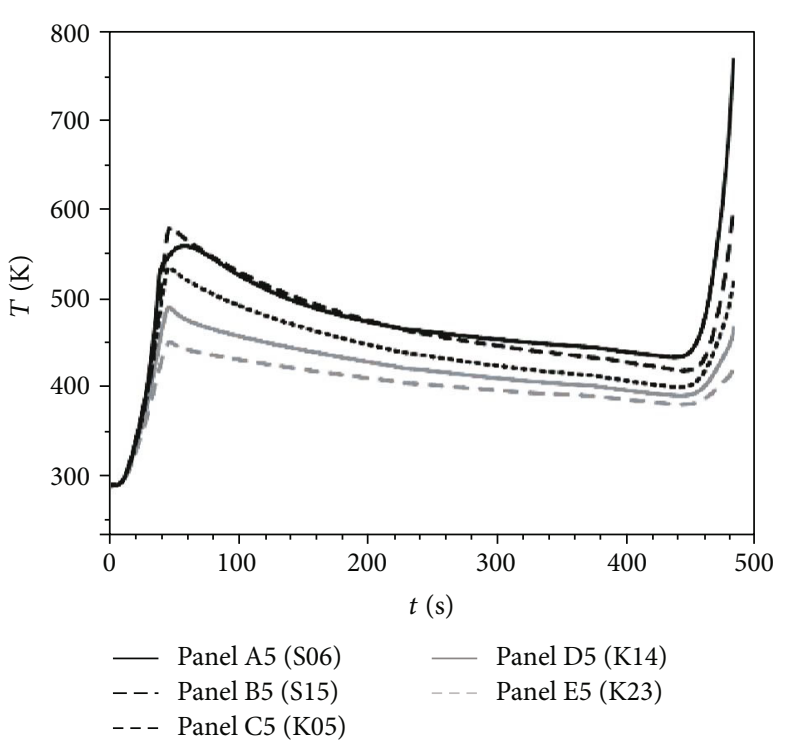

Figure 18: Measured temperatures at row 5.

but before first stage burnout. After ascent peak heating, the temperatures decrease due to the decreasing air density. The heat at the surface is transferred into the structure and vicinity by conduction and radiation until a state is reached at which the temperatures remain almost constant. This state holds on during the coast phase and flight past the apogee until reentry. First then, reincreasing convection surface heat flux leads to increasing temperatures. 


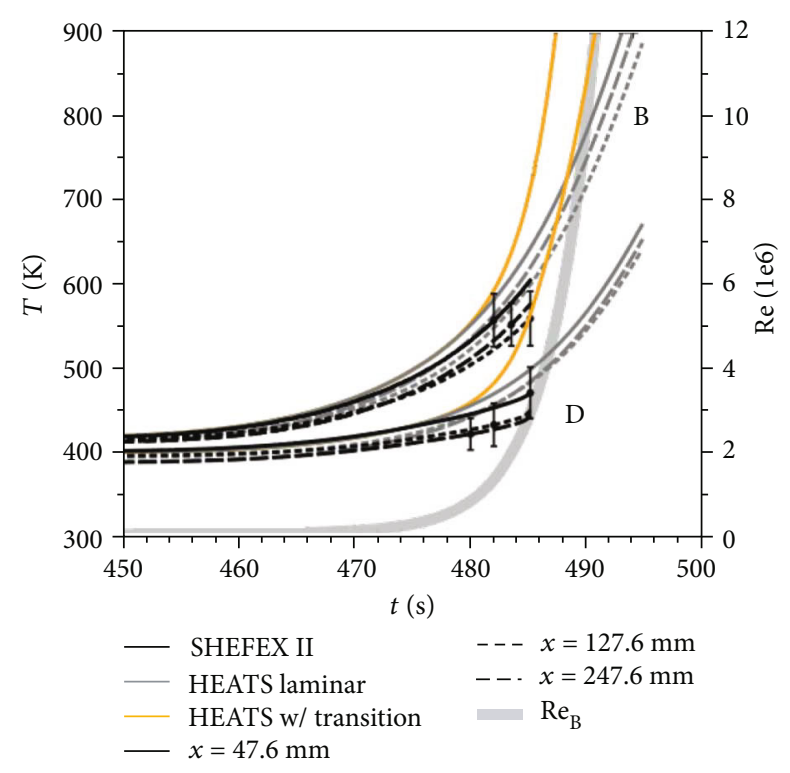

FIgURE 19: Comparison of HEATS results to SHEFEX II measurement of panels B and D.

Figure 18 shows that the shock and expansion fans, as expected, leads to the highest temperatures at the foremost segment A. At a decreasing panel deflection angle with respect to the flow, the temperatures decrease since the ambient temperatures behind the respective expansion fans decrease. Segment A, as shown in Figure 8, consists not of single panels as in the segments behind, but instead of two half shells, joined by joining elements, and an inlay in order to carry the solid sharp leading edge. The thin-walled mount, in turn, is attached to the aluminum substructure by Z-shaped CMC standoffs [39]. All of these elements act as heat sinks. This is why during ascent, the temperatures at panel A remain below those of panel B.

Figure 19 shows the measurement at panels B and D averaged over the four instrumented circumferential panels for the respective $x$-position over reentry flight time. The scatter of the values with respect to the angle of attack is represented by the scatter bars based on the standard deviation of the measurement. It can be seen that a prediction with HEATS, which takes into account a laminar-turbulent transition, overestimates the measurement by up to $23 \%$, while the laminar consideration meets the measurement with a maximum deviation of $8.4 \%$ at panel D. Although a continuous laminar flow seems unrealistic, this indicates that the flow remains laminar longer than anticipated. This effect might originate from the reattachment of the flow after the Prandtl-Meyer-expansion at the vehicle facet corners. For classification, the Reynolds number is also plotted in Figure 19.

When comparing the laminar prediction from HEATS, which neglects attachment, the deviation is small with $5.5-8.5 \%$ at $t=485.12 \mathrm{~s}$, but the measurement is systematically below the predicted temperatures. This suggests that heat is conducted away from the panel center by the central post, giving good contact to the substructure and serving as a heat sink. Overall, the flight data coincide well with the

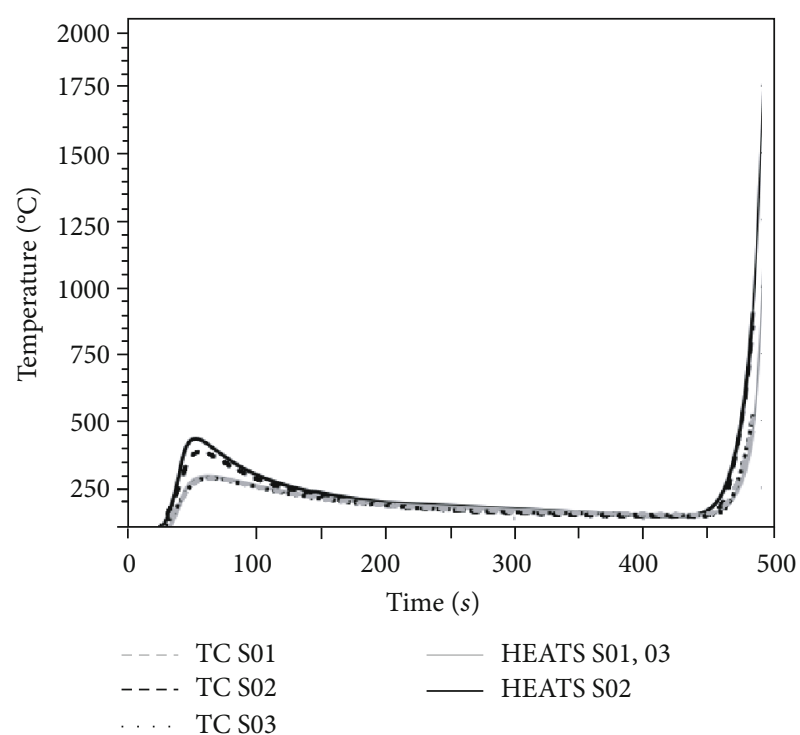

FIGURE 20: In-flight thermocouple data for the SHEFEX II trajectory (Figure 2) compared to prediction by HEATS.

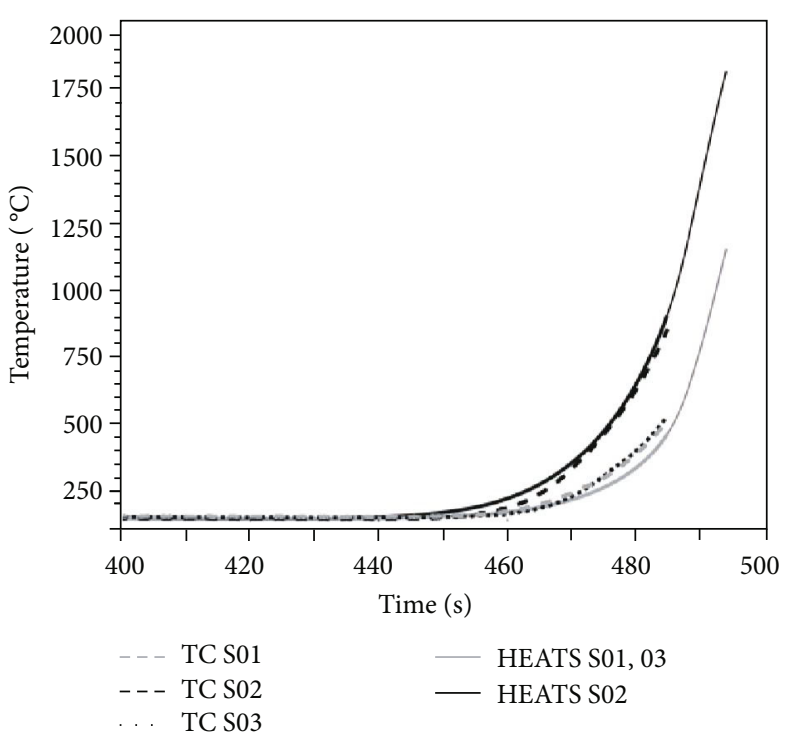

FIgURE 21: Detailed view of the atmospheric return flight phase of the SHEFEX II trajectory compared to prediction by HEATS.

expected thermal response of the faceted acreage TPS with only small deviations.

5.2. Sharp Leading Edge. Thermocouple data from the positions shown in Figure 9 are shown in dashed lines in Figure 20 and a detailed view is shown in Figure 21. Thin lines indicate the assumed flight path after the data transmission ended. Their maximum recorded temperature is $849^{\circ} \mathrm{C}$, a temperature well below the material limit of $\mathrm{C} / \mathrm{C}-\mathrm{SiC}$, at the altitude $30 \mathrm{~km}$ just before telemetry connection ended.

Applying the heat balance HEATS to the SHEFEX II return flight trajectory (Figure 2) results in the simulated temperature response shown as solid lines in Figure 21. The 


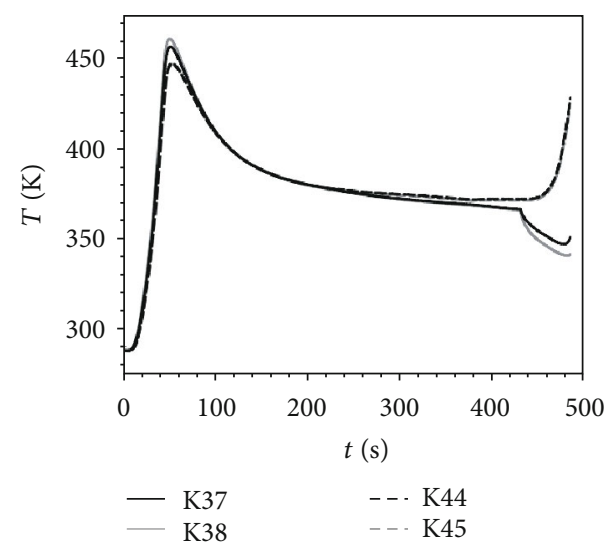

FIGURE 22: Comparison of sample temperatures on AKTiV and the reference set-up.

in-flight measurements are in good concurrence with the expectation. Differences between simulation and measurement are attributed to uncertainties in the atmosphere model and the assumption of constant material properties [39].

The subsequent flight path after telemetry ended is not exactly known. The heat balance gives the thermal response of the sharp leading edge as expected for the remaining descent as assumed in Figure 2. The temperature of the leading edge at thermocouple position TC S02 is derived as $1817^{\circ} \mathrm{C}$. The corresponding surface temperature with a maximum of $2344^{\circ} \mathrm{C}$ would have been above the material limit.

5.3. Transpiration-Cooled Experiment AKTiV. Figure 22 shows the measurement of two temperature sensors on the porous sample of the cooled experiment and the uncooled reference set-up. For thermocouple locations, see Figure 15. Cooling with $0.4 \mathrm{~g} / \mathrm{s}$ nitrogen was switched on via telecommand at $431 \mathrm{~s}$. Before that, the structure was only subject to the ambient flow and shows the typical temperature maximum at ascent peak heating $[42,45]$.

It can be seen in Figures 23 and 24 that upon the start of the coolant flow, i.e., from $431 \mathrm{~s}$, the temperatures of the panel decrease, showing that transpiration cooling is effective. This is demonstrated by measurement on the porous sample itself, but also in the film cooling region downstream of the sample. The temperature difference with respect to the uncooled reference set-up is biggest for measurement location $\mathrm{K} 38$ with $87 \mathrm{~K}$, which, according to equation (6), corresponds to a cooling efficiency of $58 \%$. Downstream from the sample, the temperature is effectively reduced by $74.5 \mathrm{~K}$ at K33, resulting in a cooling efficiency of $42 \%$.

Figures 22-24 also show the interesting effect that the temperatures reincrease after being cooled down from the timepoint of coolant switch-on. From this point, the cooling cannot compensate the increasing heat flux anymore; however, the temperatures are strongly reduced in comparison to the uncooled reference. This shows that the structure is not overcooled and still reacts to increasing heat flux. The same behaviour is predicted by the heat balances with HEATS. Figure 25 shows that the cooling is well reproduced by HEATS with only small deviations on the porous sample.

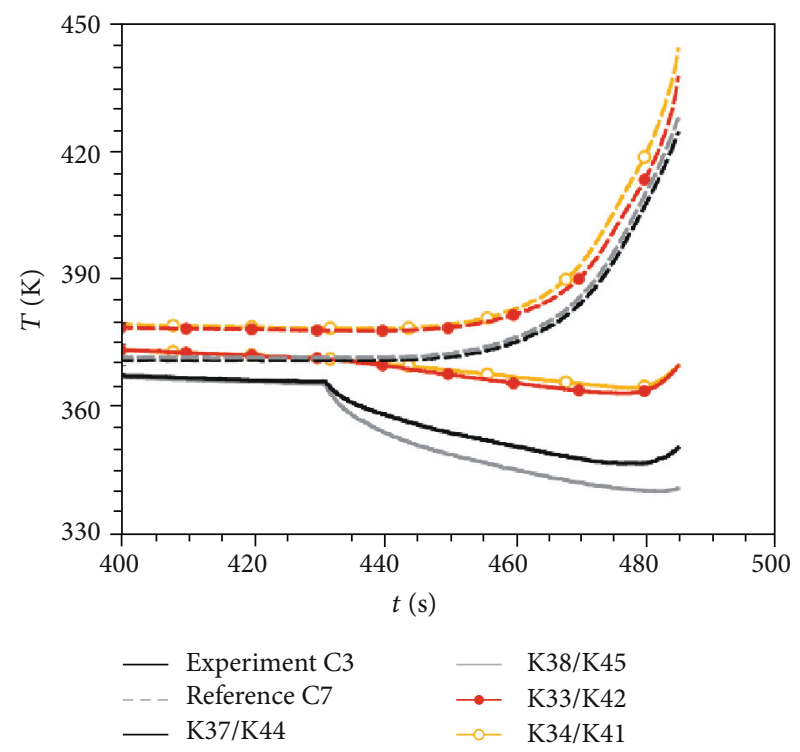

FIgUre 23: Temperatures on AKTiV and the reference set-up. Solid curves indicate thermocouple signals K29-K38 of the cooled experiment AKTiV while dashed curves represent signals K39-K46 of the uncooled reference with an identical set-up [42].

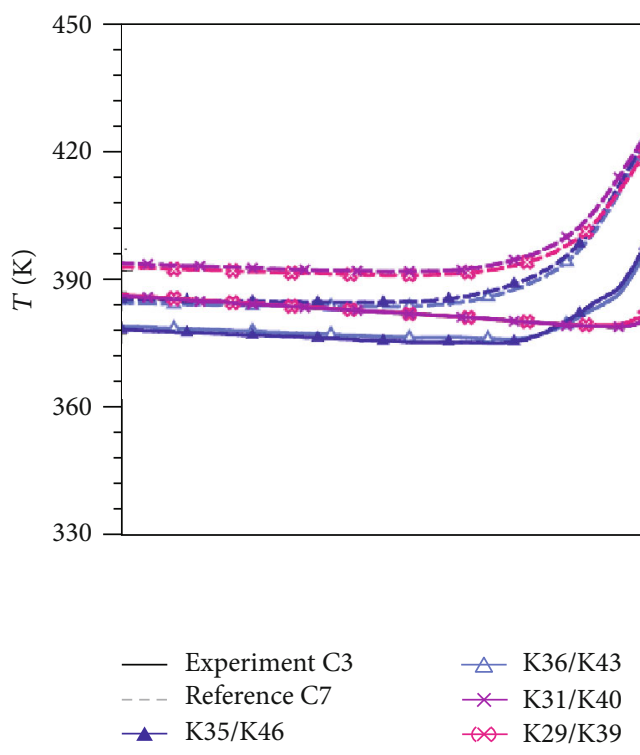

FIgURE 24: More temperatures on AKTiV and the reference set-up. Solid curves indicate thermocouple signals K29-K38 of the cooled experiment AKTiV while dashed curves represent signals K39-K46 of the uncooled reference with an identical set-up [42].

Additionally, the results of AKTiV at $t=485.12 \mathrm{~s}$ are plotted over distance $x$ from the panel edge in Figure 26. Comparison to HEATS shows thermal response as expected on the impermeable $\mathrm{C} / \mathrm{C}-\mathrm{SiC}$ panel, while the steel reservoir is identified as a major heat sink on the cooled $\mathrm{C} / \mathrm{C}$ sample. The sample temperatures had been expected to exceed those of the panel because of the lower heat conductivity of $\mathrm{C} / \mathrm{C}$ and a thinner sample thickness than that of the panel. This is, however, compensated for by the set-up with the reservoir. 


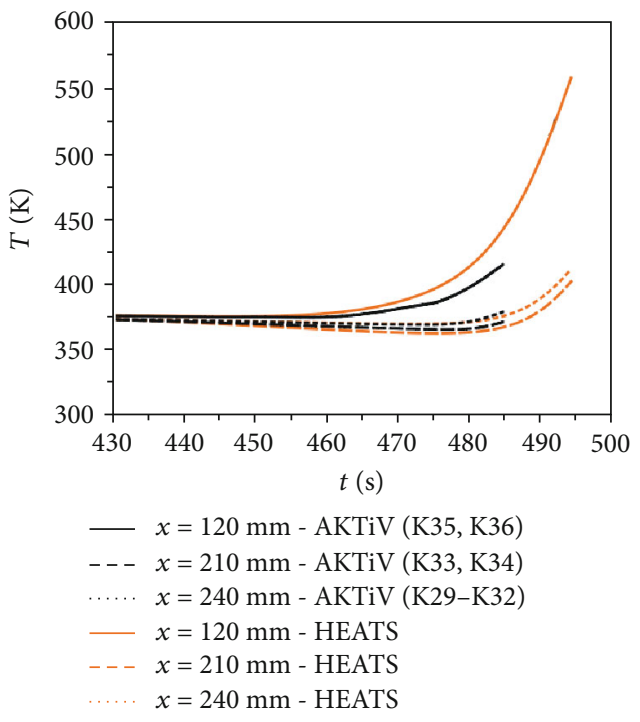

Figure 25: Comparison of HEATS with up- and downstream measurements [42].

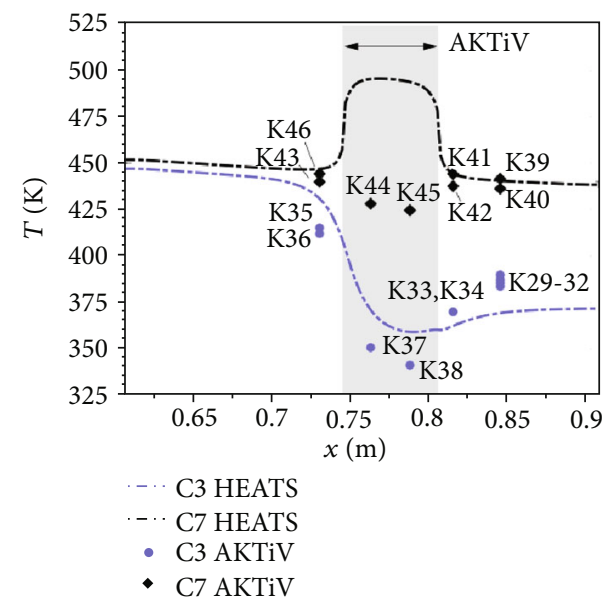

FIGURE 26: AKTiV temperatures along the panel at $t=485.12$ [42].

However, Figure 26 shows that the temperature is reduced by the coolant as shown by the graph for $\mathrm{C} 3$. The simulation with HEATS shows good agreement with the measurement values upstream and on the sample itself. The deviation from the measurement values on the sample is below $8 \%$. Also the deviation of less than $6 \%$ from the measurement downstream the sample, i.e., in the film cooling region, shows that the heat balance well estimates the thermal response of the structure.

Cooling efficiencies according to equation (6) are shown in Figure 27 for a reference coolant temperature of $T_{c}=300$ K. Figures 23 and 24 had shown that upon return from the apogee, the sensor data of AKTiV deviated from that of the reference set-up on the opposite vehicle side by an average of $8.5 \mathrm{~K}$. This deviation is not yet explained but cannot be accounted to aerodynamic effects since it originates at altitudes higher than those influenced by the atmosphere. This

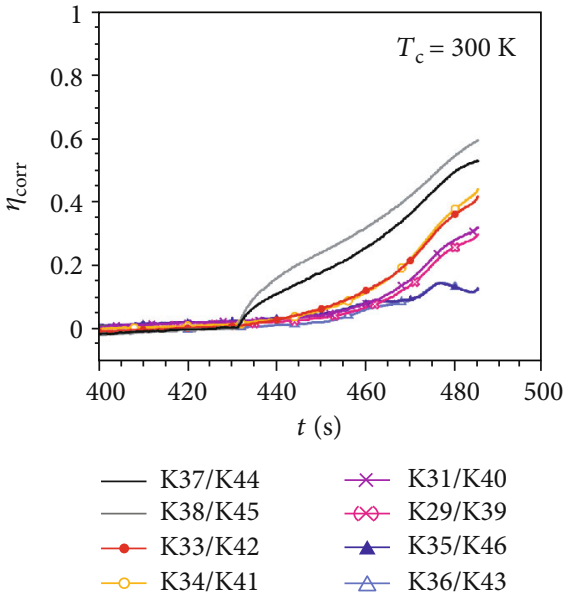

FIGURE 27: AKTiV cooling efficiency for $T_{c}=300 \mathrm{~K}[42]$.

is only an apparent cooling efficiency with an average $\eta_{\text {ini }}=$ $8.7 \%$ and has to be subtracted from the efficiencies displayed in Figure 27 . The corrected cooling efficiency $\eta_{\text {corr }}=\eta-\eta_{\text {ini }}$, thus, is $51 \%$ and $58 \%$ up- and downstream on the porous sample, respectively. Downstream of the porous sample, it decreases with sensor distance from the sample with $42 \%$ and $30 \%$. A cooling effect of the order of $11 \%$ can even be noticed upstream of the sample and it is assumed that heat conduction causes this cooling effect.

\section{Summary and Conclusion}

The recent progress in material development and the improvement of lay-up and design calculation methods allow for a reconsideration of sharp leading-edge concepts for hypersonic flight. The faceted sharp-edged flight experiment served to investigate the applicability of CMCs for (a) slender and faceted, (b) sharp-leading-edged, (c) actively cooled, and (d) controllable hypersonic vehicles. SHEFEX II has flown from the Andøya Rocket Range in Norway on June $22^{\text {nd }}$ 2012. It reached an approximately $180 \mathrm{~km}$ altitude and returned at Mach 10.2. All data were transmitted from the uncovered forebody from launch, throughout the ascent, apogee, and reentry until SHEFEX II dove behind the horizon and the transmission ended at an altitude of just below $30 \mathrm{~km}$.

Each flat TPS panel was instrumented with three thermocouples. As expected, the thermocouple readings show the highest temperatures at the foremost segment $A$. At a decreasing panel deflection angle with respect to the flow, the temperatures decrease since the ambient temperatures behind the respective expansion fans decrease. The comparison to expected temperatures predicted by a heat balance HEATS reveals heat sinks in the attachment system while the concurrence with the measurement is good with only $8 \%$ deviation.

The octagonal sharp leading edge of SHEFEX II is made from a C/C-SiC-fiber-reinforced ceramic and has a leadingedge radius of $<1 \mathrm{~mm}$. It is instrumented by three thermocouples and eight pressure ports. The maximum temperature measured during flight was $867^{\circ} \mathrm{C}$ just before transmission 
ended and were predicted with an accuracy of the order of $10 \%$. In conclusion, this shows that HEATS is a reliable tool for the prediction of the thermal response of a sharp leading edge. Although the SHEFEX II signal was lost, HEATS predicts for the anticipated subsequent flight segment that the temperature reached at the thermocouple position must have increased up to $1800^{\circ} \mathrm{C}$. In turn, the leading-edge tip is determined to have reached more than $2300^{\circ} \mathrm{C}$ just before payload split.

For the short flight time, these temperatures are considered as uncritical for the leading edge. For future entry or hypersonic flight missions, however, at higher velocity, the temperatures exceed the material limit and cooling methods have to be considered. A transpiration-cooling experiment AKTiV was therefore flown on SHEFEX II for the first time and has proven high efficiency for the cooling of a side panel. A reference set-up was located on the opposite panel. Upon start of the coolant flow, the panel temperatures are drastically reduced on the sample and in the coolant wake. As the heat flux increases, the cooled structure's temperatures also increase at their lower level. This shows that the structure is not overcooled. The efficiencies at the maximum heating are $58 \%$ on the porous sample and $42 \%$ and $30 \%$ downstream of the sample in the wake. Future investigations address the application of this technology to a sharp leading edge which is subject to severe temperature and pressure gradients.

Temporary reception of the parachute signal in the foreseen impact area indicates that the rest of the flight has passed according to plan. It can thus be concluded that the SHEFEX II has successfully withstood the aerothermal loads of the SHEFEX II flight. All structural challenges have thus been successfully solved, the flight data are within the expectation before the flight experiment, and the present TPS technologies were proven to be ready for practical use in future hypersonic flight.

\section{Data Availability}

The flight data used to support the findings of this study are included within the article.

\section{Conflicts of Interest}

The authors declare that they have no conflicts of interest.

\section{Acknowledgments}

The SHEFEX II team has greatly contributed to the payload forebody now ready for flight. Mechanical machining of the TPS structures was carried out by Florian Hofmeister, Robert Leipnitz, and Oliver Schatz. Frank Entenmann surveyed the detailed coordinates of each of the ceramic components. Our student workers Uli Beyermann, Tobias Wensky, Daniel Feldmann, Olivier Piol, Peter Leschinski, Tural Aliyev, and Sofia Giagkozoglou have also contributed to the work presented here on SHEFEX II. Part of the work presented was supported by the Helmholtz Alliance as the Helmholtz
Young Investigator's Group VH-NG-909 “High-Temperature Management in Hypersonic Flight."

\section{References}

[1] J. Longo, T. Eggers, A. Gülhan, J. Turner, and H. Weihs, "Designing flight experiments for hypersonic flow physics," in "Flight Experiments for Hypersonic Vehicle Development", RTO AVT VKI Lecture Series, RTO, Brussels, Belgium, 2005.

[2] T. Eggers, J. Longo, J. Turner et al., "The SHEFEX flight experiment - pathfinder experiment for a sky based test facility," in 14th AIAA/AHI Space Planes and Hypersonic Systems and Technologies Conference, Canberra, Australia, November 2006.

[3] J. Spies, "RLV Hopper: consolidated system concept," Acta Astronautica, vol. 53, no. 4-10, pp. 709-717, 2003.

[4] M. K. Hesse, U. Reinartz, and J. Ballmann, "Numerical computations for the RLV HOPPER/PHOENIX configuration," in 12th AIAA International Space Planes and Hypersonic Systems and Technologies, Norfolk, Virginia, December 2003.

[5] H. Weihs, J. Longo, and A. Gülhan, "The sharp edge flight experiment SHEFEX," in 4th European Workshop on Thermal Protection Systems \& Hot Structures Conference Proceedings, European Space Agency, Noordwijk, The Netherlands, 2002.

[6] D. Strohmeyer, T. Eggers, and M. Haupt, "Waverider aerodynamics and preliminary design for two-stage-to-orbit missions, part 1," Journal of Spacecraft and Rockets, vol. 35, no. 4, pp. 450-458, 1998.

[7] T. Eggers, P. Novelli, and M. Haupt, "Design studies of the JAPHAR experimental vehicle for dual mode ramjet demonstration," in 10th AIAA/NAL-NASDA-ISAS International Space Planes and Hypersonic Systems and Technologies Conference, Kyoto, Japan, April 2001.

[8] J. Arnold, S. Johnson, and P. Wercinski, "SHARP: NASA's research and development activities in ultra-high temperature ceramic nose caps and leading edges for future space transportation vehicles," in 52nd International Astronautical Congress, Toulouse, France, 2001.

[9] T. Barth, "Aero- and thermodynamic analysis of SHEFEX I," Engineering Applications of Computational Fluid Mechanics, vol. 2, no. 1, pp. 76-84, 2008.

[10] A. Stamminger, "Atmospheric re-entry analysis of sounding rocket payloads," in 18th ESA Symposium on European Rocket and Balloon Programmes and Related Research, pp. 193-198, Visby, Sweden, 2007.

[11] T. Eggers, J. Longo, A. Gülhan, M. Hörschgen, A. Stamminger, and J. Turner, "Preliminary postflight data analysis of the SHEFEX experiment," in 1st International ARA-Days, Arcachon, France, July 2006.

[12] A. Bierig and S. Lorenz, "Development of the aerodynamic control system for the hypersonic flight experiment SHEFEX II," in Deutscher Luft- und Raumfahrt Kongress (DLRK) 2013, Stuttgart, Germany, September 2013.

[13] S. Lorenz and A. Bierig, "Robustness analysis related to the control design of the SHEFEX-II hypersonic canard control experiment," in AIAA Guidance, Navigation, and Control (GNC) Conference, Boston, MA, August 2013.

[14] J. Turner, J. Ettl, M. H*orschgen-Eggers, P. Turner, and W. Jung, "SHEFEX II vehicle and subsystem design, flight performance and their application to future hypersonic missions," in Proceedings of the 21st ESA Symposium on European Rocket 
and Balloon Programmes and Related Research, No. ESA SP-721, European Space Agency, pp. 137-142, Noordwijk, the Netherlands, 2013.

[15] J. Ettl and J. Turner, "SHEFEX II - precession control system," in SpaceOps 2014 Conference, Pasadena, CA, May 2014.

[16] H. Oertel Jr., Aerothermodynamik, Springer-Verlag, Berlin Heidelberg, 1994.

[17] J. Anderson, Hypersonic and High Temperature Gas Dynamics, McGraw-Hill, New York, 1989.

[18] H. Boehrk, O. Piol, and M. Kuhn, "Heat balance of a transpiration-cooled heat shield," Journal of Thermophysics and Heat Transfer, vol. 24, no. 3, pp. 581-588, 2010.

[19] H. Böhrk, J. Martinez Schramm, V. Wartemann, T. Eggers, and K. Hannemann, "Shock tube testing of the transpirationcooled heat shield experiment AKTiV," in 18th AIAA/3AF International Space Planes and Hypersonic Systems and Technologies Conference, Tours, France, September 2012.

[20] W. Krenkel, Keramische Verbundwerkstoffe, Wiley-VCH, Weinheim, 2002.

[21] R. Brandt, M. Frieß, and G. Neuer, "Thermal conductivity, specific heat capacity, and emissivity of ceramic matrix composities at high temperatures," High Temperatures - High Pressures, vol. 35/36, no. 2, pp. 169-177, 2003.

[22] H. Hald and T. Ullmann, "Reentry flight and ground testing experience with hot structures of $\mathrm{C} / \mathrm{C}-\mathrm{SiC}$ material," in 44th AIAA/ASME/ASCE/AHS/ASC Structures, Structural Dynamics, and Materials Conference, Norfolk, VA, April 2003.

[23] B. Heidenreich, S. Hofmann, M. Keck, R. Jemmali, M. Friefi $\beta$, and $\mathrm{D}$. Koch, "C/C-SiC materials based on melt infiltration manufacturing methods and experiences from serial production," in High temperature ceramic matrix composites 8: ceramic transactions, L. Zhang and D. Jiang, Eds., pp. 295310, The American Ceramic Society, John Wiley and Sons, Hoboken, NJ, 2014.

[24] H. Hald, T. Reimer, D. Petersen, M. Bickel, and U. Trabandt, "A CMC-based thermal protection system for the cryogenictank reusable launch vehicles," in 3rd European European Workshop on Thermal Protection Systems, ESTEC, Noordwijk, The Netherlands, March 1998.

[25] H. Weihs, "A new high temperature joining method," in Proceedings of the Advanced Materials for Lightweight Structures, No. ESA WPP-070, ESTEC, pp. 91-96, Noordwijk, The Netherlands, 1994.

[26] A. Gülhan, F. Siebe, T. Thiele, D. Neeb, J. Turner, and J. Ettl, "Sharp edge flight experiment-II instrumentation challenges and selected flight data," Journal of Spacecraft and Rockets, vol. 51, no. 1, pp. 175-186, 2014.

[27] A. Gülhan, D. Neeb, T. Thiele, and F. Siebe, “Aerothermal postflight analysis of the sharp edge flight experiment-II," Journal of Spacecraft and Rockets, vol. 53, no. 1, pp. 153-177, 2016.

[28] D. Hänsel, H. Hald, F. Rühle, T. Reimer, and H. Weihs, "Development of a joining element for high temperature constructions," in 3rd European Workshop on Thermal Protection Systems, ESTEC, Noordwijk, The Netherlands, March 1998.

[29] M. Ortelt, F. Ruehle, H. Hald, and H. Weihs, "Dynamic qualification of a new CMC fastener," in High Temperature Ceramic Matrix Composites, ECI Symposium Series, W. Krenkel, R. Naslain, and H. Schneider, Eds., pp. 760766, Wiley-VCH Verlag GmbH \& Co. KGaA, Weinheim, 2001.
[30] H. Böhrk and U. Beyermann, "Secure tightening of a CMC fastener for the heat shield of re-entry vehicles," Composite Structures, vol. 92, no. 1, pp. 107-112, 2010.

[31] H. Böhrk, H. Elsäßer, and H. Weihs, "Flight data from the faceted TPS on SHEFEX II," in Proceedings of the 8th European Symposium on Aerothermodynamics for Space Vehicles, Lisbon, Portugal, 2015.

[32] H. Weihs, J. Turner, and J. Longo, "The sharp edge flight experiment SHEFEX II, a mission overview and status," in 15th AIAA International Space Planes and Hypersonic Systems and Technologies Conference, Dayton, Ohio, USA, April 2008.

[33] P. Mechnich, W. Braue, H. Schneider, U. Koch, B. Esser, and A. Gülhan, "Thermal response of WHIPOX-Type all-oxide ceramic matrix composites during reentry simulation in the DLR-LBK arc-heated facility," in 5th European Symposium on Aerothermodynamics for Space Vehicles, European Space Agency, Köln, Germany, 2005.

[34] A. Preci, G. Herdrich, and M. Auweter-Kurtz, "The combined sensor system COMPARE for SHEFEX II," in 16th AIAA/DLR/DGLR International Space Planes and Hypersonic Systems and Technologies Conference, Bremen, Germany, October 2009.

[35] A. Preci, G. Herdrich, S. Faoulas, and M. Auweter-Kurtz, "Assembly, integration and test of the sensor system COMPARE for SHEFEX II," in 42nd AIAA Thermophysics Conference, Honolulu, USA, June 2011.

[36] W. Fischer and R. Knoche, "ASTRIUM's TPS experiment on SHEFEX II-design \& analyses," in 6th European Workshop on Thermal Protection Systems \& Hot Structures Conference Proceedings, European Space Agency, Stuttgart, Germany, April 2009.

[37] R. Knoche, E. Werth, S. Goëck, and M. Weth, "Thermomechanical design of the ASTRIUM C/SiC experiment on SHEFEX II," in 7th International Conference on High Temperature Ceramic Matrix Composites, Bayreuth, Germany, September 2010.

[38] T. Thiele, D. Neeb, and A. Gülhan, "Post-flight hypersonic ground experiments and FADS flight data evaluation for the SHEFEX-II configuration," in Proceedings of the 8th European Symposium on Aerothermodynamics for Space Vehicles, Lisbon, Portugal, 2015.

[39] H. Böhrk, C. Dittert, H. Weihs, T. Thiele, and A. Gülhan, "Sharp leading edge at hypersonic flight: modeling and flight measurement," Journal of Spacecraft and Rockets, vol. 51, no. 5, pp. 1753-1760, 2014.

[40] S. Ghadiani, "A multiphasic continuum mechanical model for design investigations of an effusion cooled rocket thrust chamber, Ph.D. thesis," Universit" at Stuttgart, 2005.

[41] H. Böhrk, "Transpiration cooling at hypersonic flight - AKTiV on SHEFEX II," in 11th AIAA/ASME Joint Thermophysics and Heat Transfer Conference, Atlanta, GA, June 2014.

[42] H. Böhrk, "Transpiration-cooled hypersonic flight experiment: set-up, flight-measurement and reconstruction," Journal of Spacecraft and Rockets, vol. 52, no. 3, pp. 674-683, 2015.

[43] H. Elsäßer and H. Weihs, "Design and thermo-mechanical analysis of the aerodynamic control surfaces on SHEFEX-II," in 6th European Workshop on Thermal Protection Systems \& Hot Structures Conference Proceedings, European Space Agency, Stuttgart, Germany, April 2009.

[44] T. Thiele, F. Siebe, and A. Gülhan, "SHEFEX II flight instrumentation and preparation of post flight analysis," in 7 th 
Symposium on Aerothermodynamics for Space Vehicles, European Space Agency, Brugge, Belgium, May 2011.

[45] E. Bafekrpour and H. Böhrk, "10 Heat flux reduction by transpiration-cooling of CMCs for space applications," in Advanced Composite Materials: Properties and Applications, pp. 468-496, De Gruyter Open, Warsaw, Poland, 2017.

[46] M. Schmücker and P. Mechnich, "All-oxide ceramic matrix composites with porous matrices," in Ceramic Matrix Composites, Fiber-Reinforced Ceramics and Their Application, W. Krenkel, Ed., pp. 205-229, Wiley-VCH, Weihnheim, 2008. 


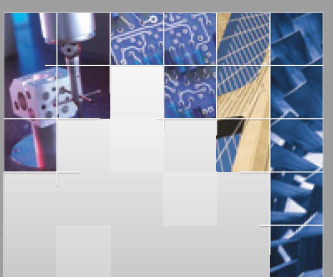

\section{Enfincering}
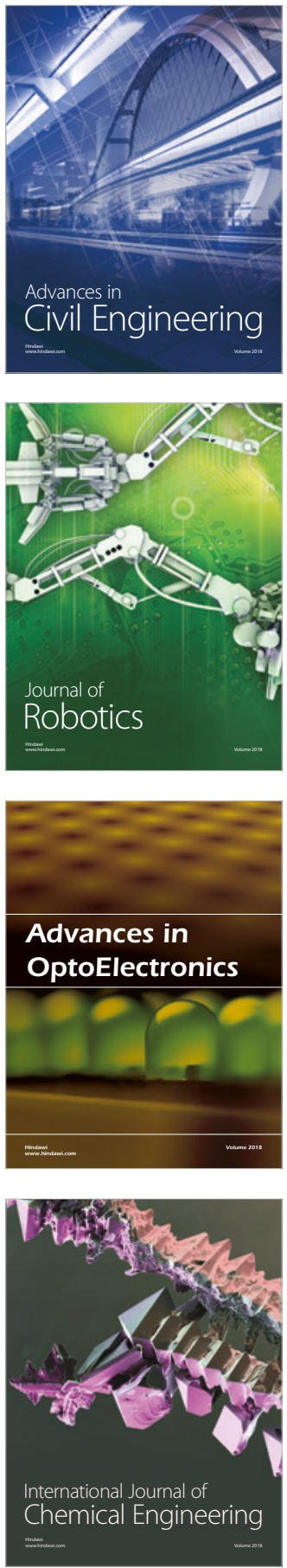

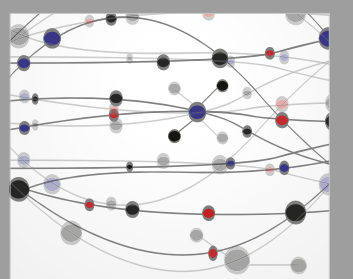

\section{Rotating \\ Machinery}

The Scientific World Journal

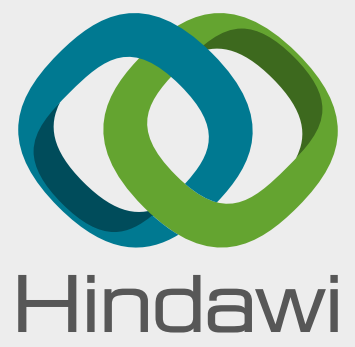

Submit your manuscripts at

www.hindawi.com
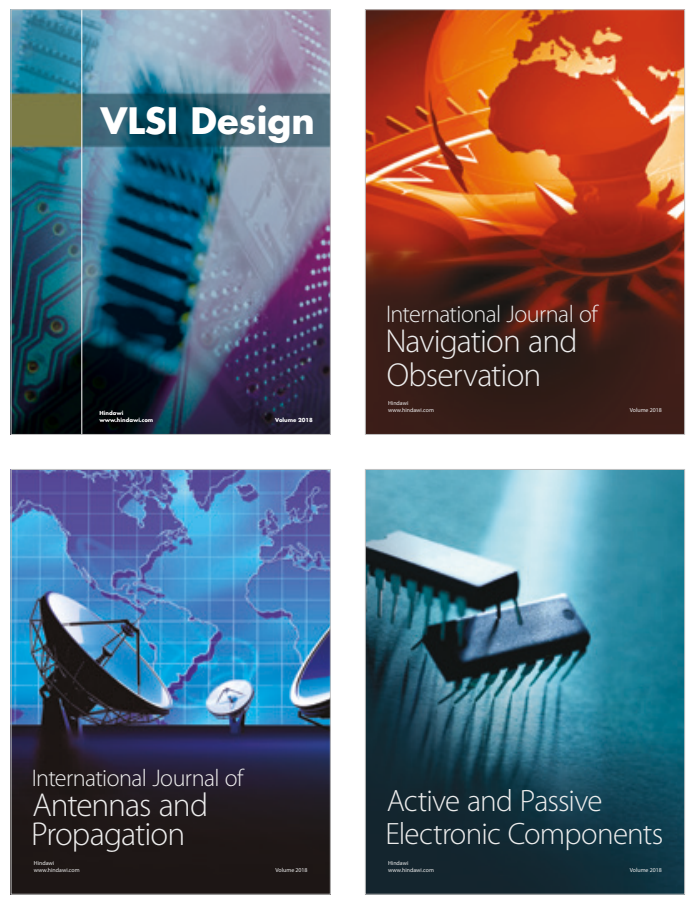
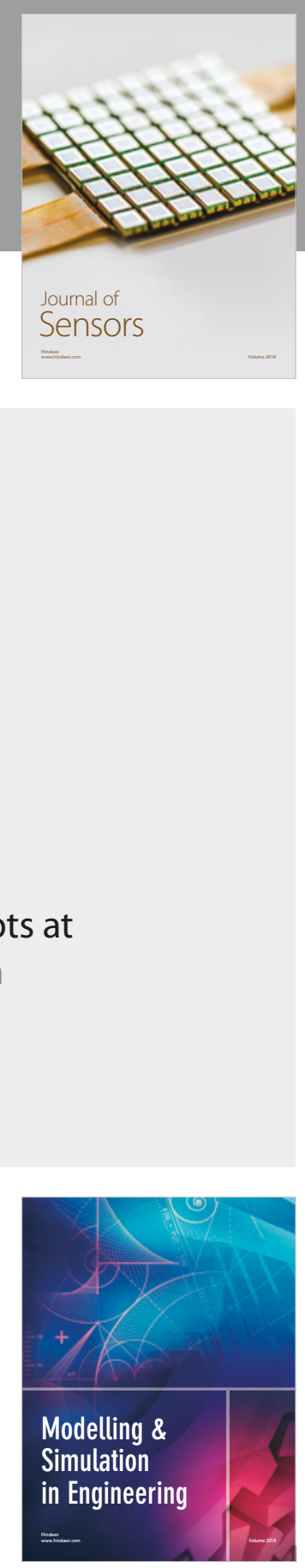

\section{Advances \\ Multimedia}
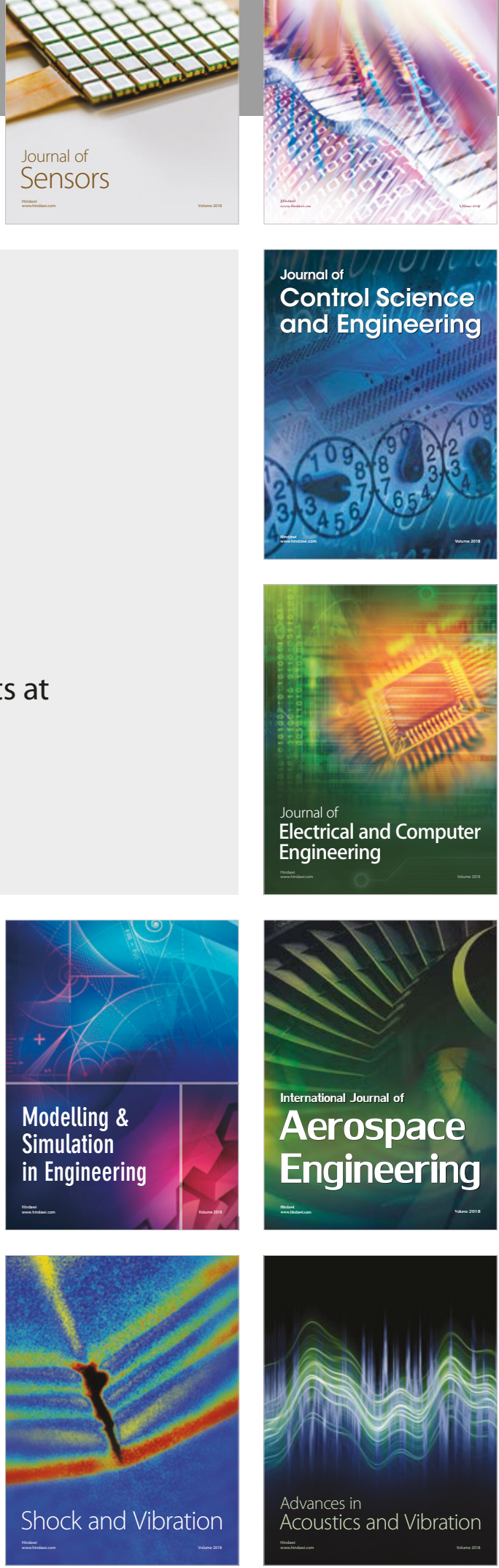